\title{
Design and Numerical Analysis of a Novel Rectangular PCF (R-PCF)-Based Biochemical Sensor (BCS) in the THz Regime
}

\author{
Abdullah Al-Mamun Bulbul $\mathbb{D}^{1},{ }^{1}$ Abbas Z. Kouzani $\left(\mathbb{D},{ }^{2}\right.$ M. A. Parvez Mahmud $\left(\mathbb{D},{ }^{2}\right.$ \\ and Abdullah-Al Nahid $\mathbb{D}^{1}$ \\ ${ }^{1}$ Electronics and Communication Engineering Discipline, Khulna University, Khulna 9208, Bangladesh \\ ${ }^{2}$ School of Engineering, Deakin University, Geelong, VIC 3216, Australia \\ Correspondence should be addressed to Abdullah-Al Nahid; nahid.ece.ku@ku.ac.bd
}

Received 7 January 2021; Revised 22 January 2021; Accepted 5 February 2021; Published 19 February 2021

Academic Editor: Sulaiman W. Harun

Copyright (c) 2021 Abdullah Al-Mamun Bulbul et al. This is an open access article distributed under the Creative Commons Attribution License, which permits unrestricted use, distribution, and reproduction in any medium, provided the original work is properly cited.

\begin{abstract}
A novel PCF-based sensor has been presented in this paper to sense different chemicals and biocomponents. The proposed biochemical sensor (BCS) comprises a simple arrangement of rectangular holes. The competence of this BCS in detecting analytes is evaluated employing the full-vector finite element method (FEM). Performance metrics prove the competence of this BCS in sensing various analytes that have a refractive index in the range of 1.33-1.48. The proposed BCS shows ultralower values for both the bulk absorption and confinement loss. This BCS attains a maximum of about $95.82 \%$ relative sensitivity at $2.5 \mathrm{THz}$. Also, the dispersion for this sensor is only $0.12 \pm 0.011 \mathrm{ps} / \mathrm{THz} / \mathrm{cm}$ at the same point of interest. These results prove that the proposed BCS will play a key role in sensing toxic chemicals, illegal drugs, biocomponents, etc. Besides, the simple rectangle-based PCF structure ensures the feasibility of fabrication by practicing the existing fabrication strategies.
\end{abstract}

\section{Introduction}

The terahertz $(\mathrm{THz})$ band is gaining high popularity as an apposite operating region for diverse application fields like spectroscopy, sensing, astrophysics, hereditary, biomedical, and telecommunication [1-8]. This band offers a broad frequency band extending from 0.1 to $10 \mathrm{THz}$. An entire $\mathrm{THz}$ system requires 3 basic elements that include the waveguide, source, and detector. The development of $\mathrm{THz}$ source and detector elements in recent years has accelerated THz-based sensing. Besides, numerous $\mathrm{THz}$ waveguides, for instance, the Bragg waveguide [9], metal wires [10], metallic tubes [11], etc., have been proposed recently. However, most of these waveguides fail to achieve higher relative sensitivity. To avoid this problem, several photonic crystal fibre (PCF)-based $\mathrm{THz}$ waveguides have been proposed in recent years.

Researchers have successfully modelled PCF-based chemical and biosensors functioning in the $\mathrm{THz}$ band. As a sensor, PCF is applied to sense multiple chemical and biological elements, for example, the detection of fuel adulteration [12], salinity [13], bane chemicals [14], blood components [5], and cholesterol [15]. This sensor resolves the snags of conventional fibres by maintaining higher diversity and standard values for optical parameters. Besides, this type of sensor is much faster than the existing detection systems. One of the splendid properties of this sensor is the tunability of the optical parameters through careful adjustment of the size, position, and structure of the core and cladding hole of the PCF. Also, this type of sensor offers a lot more advantageous features that includes higher relative sensitivity, lower material and confinement loss (CL), light weight, robustness, cheaper, etc. All these features have widened the potential application of PCF-based sensors in chemical and bio-sensing applications, which includes the study of RNA and DNA [16-18], detection of cancerous cells [19-21], classification and detection of alcohol [22-26], detection of formalin $[27,28]$, and surface plasmon resonance-based biosensors [29-31].

Since the last decades, several refractive index (RI)based chemical and biosensors have been proposed. In [5], 
a PCF-based biosensor is proposed. The model is particularly aimed to sense blood components based on RI. The model maintains low CL, but it shows a high effective area (EA) of about $166000 \mu \mathrm{m}^{2}$ at $1.5 \mathrm{THz}$. Besides, the relative sensitivity attained for the sensor is only $79.9 \%$ and the dispersion is higher. In [32], a PCF-based chemical sensor is proposed where the cladding holes are heptagonally positioned. The sensing performance of the sensor has been evaluated while detecting benzene, ethanol, and water. The sensor exhibits lower CL, but the relative sensitivity attained for the sensor is only $63.24 \%$ at $1.0 \mathrm{THz}$. Several key optical parameters including numerical aperture and effective material loss (EML) have not been determined for the sensor. Another PCF-based chemical sensor is presented in [14]. The sensor is modelled to detect bane chemicals, namely sarin, soman, and tabun. The sensor exposes $0.009 \mathrm{~cm}^{-1}$ EML and $1.71 \times 10^{-14} \mathrm{~cm}^{-1} \mathrm{CL}$. The relative sensitivity attained for the sensor is $94.4 \%$ for tabun at $1.8 \mathrm{THz}$. However, the true sensing region and numerical aperture are ignored for the sensor. A PCF-based $\mathrm{NaCl}$ sensor is presented in [33], where the core of the sensor comprises tetra-rectangles. The sensor shows $91.5 \%$ relative sensitivity and $0.004 \mathrm{~cm}^{-1} \mathrm{EML}$, but it has a higher EA of $397340 \mu \mathrm{m}^{2}$ at $1.8 \mathrm{THz}$. Recently, a PCF-based chemical sensor is proposed in [34] to detect ethanol, benzene, and water. The sensor shows $3.02 \times 10^{-8} \mathrm{~cm}^{-1} \mathrm{CL}$, but the EML has not been estimated for this sensor. However, the sensor has achieved almost $78.1 \%$ relative sensitivity for benzene. In [35], a Ag-graphene-coated surface plasmon resonance (SPR) sensor is proposed to sense analytes with RI ranging from 1.33 to 1.41 . This model shows $12.6 \mu \mathrm{m} / \mathrm{RIU}$ wavelength sensitivity and $79.4 \times 10^{-5}$ RIU resolution, but this model suffers from high CL of about $1.75 \times 10^{2} \mathrm{~dB} / \mathrm{cm}$ at $625 \mathrm{~nm}$ for water. Besides, this sensor comprises complex $\mathrm{H}$-shaped PCF. In [36], another H-shaped PCF-based SPR sensor is presented to enhance the sensing range. This sensor can detect analytes with 1.33 to $1.49 \mathrm{RI}$. This model exhibits only $1.2 \times 10^{3} \mathrm{~nm} / \mathrm{RIU}$ sensitivity and a high peak loss of $14.34 \mathrm{~dB} / \mathrm{cm}$ for water.

Most of the existing hollow and porous core PCF sensors are particularly modelled to detect any specific analyte or a group of correlated analytes. Also, most of the available sensor models fail to attain higher relative sensitivity and lower losses at the same time, whereas SPR sensors have a RI limit as most of the SPR sensors fail to effectively sense the analytes with RI greater than 1.41 [35, 37-40]. However, most of the existing sensors are modelled with a complex PCF structure that includes a compound arrangement of air holes. This complex structure will certainly increase fabrication constraints. Hence, there is still scope to model a biochemical sensor (BCS) based on fabrication-friendly PCF structure that will be capable to sense a wide variety of chemicals and biocomponents.

In this paper, a simple rectangle-based PCF (R-PCF) structure has been modelled as a BCS. The proposed R-PCF structure has been numerically explored in the $\mathrm{THz}$ band in the range of 1.5-4.0 THz. Optical parameters have been studied for the proposed BCS to examine the sensing performance. This study has been carried out for the analytes with the RI ranging from 1.33 to 1.48 . In addition to getting the typical values for all the performance metrics, one of the key objectives of this study is to present a highly fabrication-friendly BCS, which is ensured by the presence of only rectangular holes in the PCF structure. R-PCF ensures heterodyne detection, and several sensors based on R-PCF have been proposed [41-45]. Besides, asymmetrical PCF structures comprising rectangles have already been implemented [46, 47].

\section{Sensor Design}

This paper focuses on modelling a novel, uniform, and simple BCS based on PCF. The PCF-based sensor was modelled using FEM-based software. The $x-y$ plane representation of the BCS is depicted in Figure 1. The core region of the sensor contains a single rectangle, which is denoted by $\mathrm{Cr}$ in the figure. The height of $\mathrm{Cr}$ is $400 \mu \mathrm{m}$, whereas the width of it is $410 \mu \mathrm{m}$. The cladding area is modelled through the simple arrangement of eight rectangular air holes. These eight rectangles can be grouped into two different classes based on their similarities in height and width. These two types of cladding rectangles are denoted by $C l_{1}$ and $C l_{2}$. The width and height of $C l_{1}$ are $200 \mu \mathrm{m}$ and $1000 \mu \mathrm{m}$ individually. On the other hand, the width and height of $\mathrm{Cl}_{2}$ are $200 \mu \mathrm{m}$ and $400 \mu \mathrm{m}$ exclusively. The radius of the sensor is $750 \mu \mathrm{m}$, including a $75 \mu \mathrm{m}(10 \%$ of the radius) perfectly matched layer (PML) at the outer layer. The strut, the gap between two consecutive rectangles, is $10 \mu \mathrm{m}$ for this PCF-based sensor. Multiple fibre materials are available that include silica, zeonex, topas, etc. [48-50]. Various splendid properties of zeonex and topas have influenced the researchers to select them as the fibre material. Both of them have a fixed RI of 1.53, lower dispersion, and lower material loss in the $\mathrm{THz}$ band. However, zeonex has some additional features; for instance, higher chemical resistance and glass transition temperature $[49,50]$. These two features are highly desired in the successful fabrication of any PCF. Hence, zeonex is chosen to be the fibre substance for the proposed BCS. The light propagation profile in the $x$ and $y$ polarization mode (PoM) are pictured in Figures 2(a) and 2(b), respectively, while sensing the analyte with $1.44 \mathrm{RI}$. This figure reveals the fact that propagating wave is highly confined within the core region.

The experimental setup of PCF-based models in sensing applications has been described in several papers [51-54]. The model represented in Figure 1 has resulted from the trial and error method. Through modelling different structures and comparing their optical parameters, this model has been chosen due to its dominant results. We have denoted this model as the optimum (OPT) model. Keeping the strut value constant, we have tuned the OPT model by $\pm 10 \%$ to represent a comparison among their optical parameters and justify the selection of the OPT model as the proposed BCS in this paper. The design parameters for the two models resulted from the tuning along with the OPT model are represented in Table 1 that includes the respective width $(W)$ and height $(H)$ of each rectangle. 


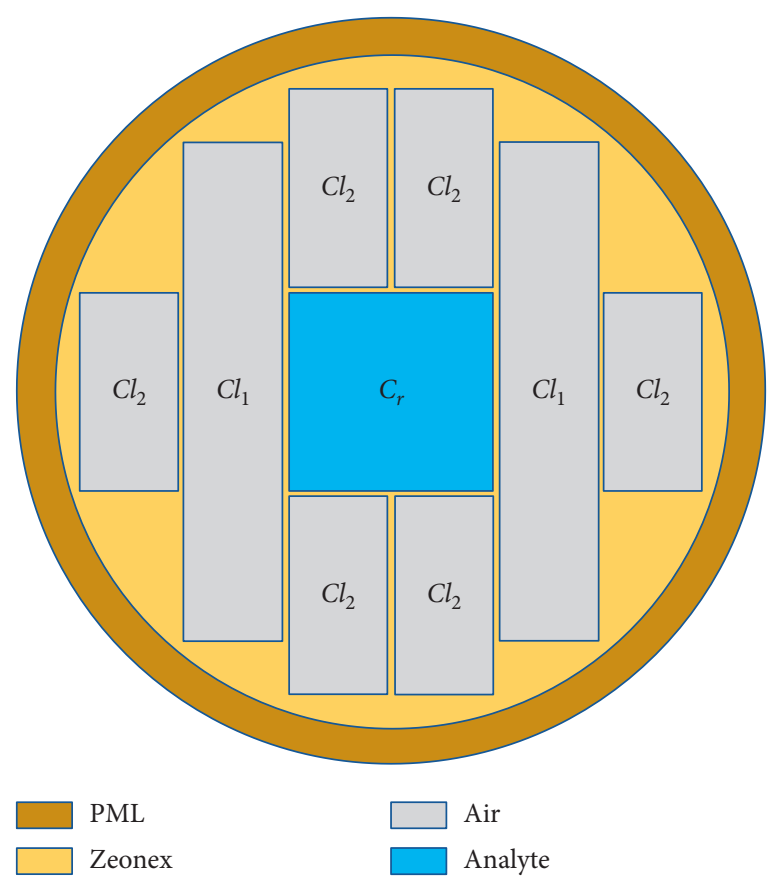

FIGURE 1: The $x-y$ plane representation of the proposed R-PCF-based BCS.

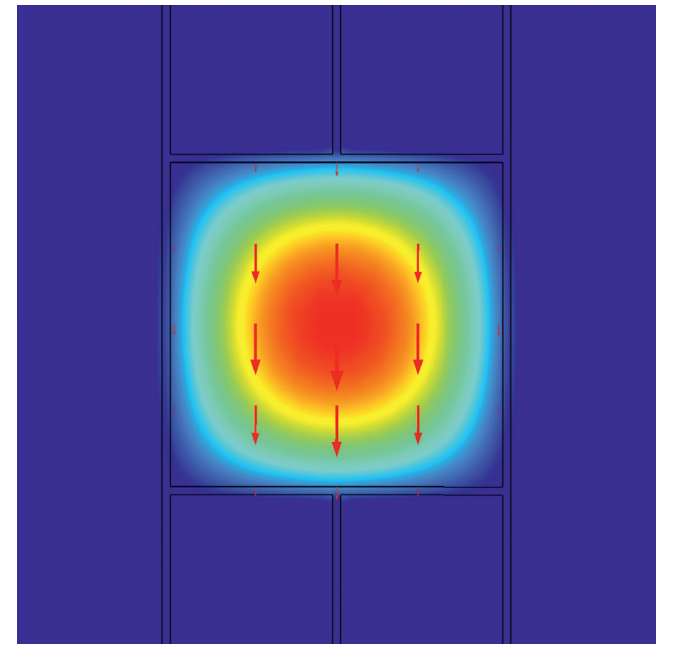

(a)

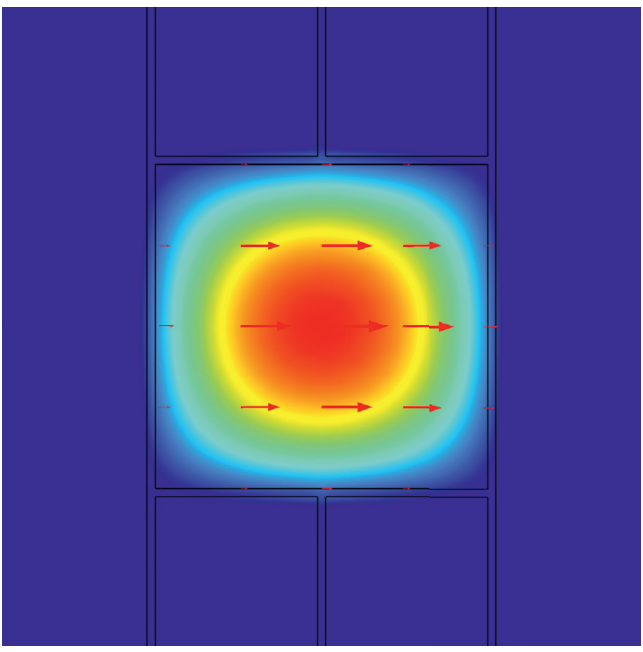

(b)

FIgURE 2: Wave propagation profile for the proposed R-PCF-based BCS. (a) $x$-PoM and (b) $y$-PoM.

TABle 1: Design parameters for three variations of the sensor model.

\begin{tabular}{lccccccccc}
\hline Model & Radius $(\mu \mathrm{m})$ & $\mathrm{PML}(\mu \mathrm{m})$ & Strut $(\mu \mathrm{m})$ & $C r(W)(\mu \mathrm{m})$ & $C r(H)(\mu \mathrm{m})$ & $C l_{1}(W)(\mu \mathrm{m})$ & $C l_{1}(H)(\mu \mathrm{m})$ & $C l_{2}(W)(\mu \mathrm{m})$ & $C l_{2}(H)(\mu \mathrm{m})$ \\
\hline OPT $-10 \%$ & 675 & 67.5 & 10 & 370 & 360 & 180 & 900 & 180 & 360 \\
OPT & 750 & 75 & 10 & 410 & 400 & 200 & 1000 & 200 & 400 \\
OPT $+10 \%$ & 825 & 82.5 & 10 & 450 & 440 & 220 & 1100 & 220 \\
\hline
\end{tabular}




\section{Fabrication Feasibilities}

In earlier stages, PCF fabrication was considered to be implemented using the stack and draw method [55], but this method fails to satisfactorily fabricate the PCF models with a complex and asymmetrical arrangement of holes [56]. To resolve these issues, several more methods have been advanced, which include drilling [57], sol-gel [58], extrusion [59], 3D-printing [46], etc. These methods are capable to fabricate complex PCF structures. The sol-gel method can potentially perform the fabrication of the PCF model with circular holes. On the other hand, both the 3D-printing and extrusion methods fabricate the asymmetrical PCF models, which include rectangular, square, and elliptical holes. The proposed BCS comprises a mono-rectangular core and a cladding with eight rectangular air holes. Hence, both 3Dprinting and extrusion will be a suitable choice to fabricate the proposed R-PCF-based BCS. Besides, the fibre with rectangular holes guarantees the heterodyne detection $[41,42]$. A few asymmetrical PCF models have been fabricated recently by the Max Planck Institute [46, 47]. The institute has successfully fabricated different PCF models comprising the elliptic, rectangle, etc. This clearly ensures the feasible fabrication of the proposed PCF structure comprising a simple arrangement of rectangles using the existing fabrication strategies.

The core of the BCS needs to be infiltrated with the target sample. There are several available techniques for the selective filling of PCF; for instance, selective filling by collapsing air holes [60], by splicing single-mode fibre [61], by femtosecond laser micromachining [62], etc. Among these strategies, we prefer the selective filling by the femtosecond laser micromachining method. This method comprises three steps. First, the PCF is spliced with a normal single-mode fibre. Then, the single-mode fibre is cut near to spliced junction using FL. Finally, selective laser drilling is performed to make a path to the core or target holes using FL. Through these three steps, the fibre will be prepared to be infiltrated with the target sample. The method has proved its higher efficiency, preciseness, and flexibility, and thereby, it has become a dependable technique of SF [63].

\section{Mathematical Methods for Sensing Performance Evaluation}

To assess the potentiality of the presented BCS in this paper, several optical parameters need to be calculated. These parameters are estimated separately for each analyte. Filling the core with the target analyte, light is injected into the core. Though the light should be bound into the core, a portion of light spreads outside the core region. The true sensing area, also known as the EA, is the measure of light spreading. The EA is evaluated using the following equation, where $E$ defines the transverse electric field $[5,33]$.

$$
\mathrm{EA}=\frac{\left(\iint|E|^{2} \mathrm{~d} x \mathrm{~d} y\right)^{2}}{\iint|E|^{4} \mathrm{~d} x \mathrm{~d} y}, \mu \mathrm{m}^{2} .
$$

The numerical aperture (NA) is a measure of the range of angles of the incident light that can enter and exit from a fibre. It is a unitless parameter, which is a function of the EA, the speed of light $(c)$, and the operating frequency $(f)$. Higher NA is desirable for sensing applications, and this desired value results from lower EA. The value for this parameter is calculated using the folllowing equation [64]:

$$
\mathrm{NA}=\frac{1}{\sqrt{1+\pi f^{2}(\mathrm{EA})^{2} / c^{2}}} .
$$

The EML is the loss of optical power due to the absorption of the fibre materials. Zeonex, the fibre material of the proposed BCS, is responsible for this loss. Appropriate designing of the PCF model and lessening the background region will keep the EML at a negligible level. Following the perturbation theory $[33,65]$, equation (3) has been used to compute this key parameter for the proposed BCS.

$$
\mathrm{EML}=\left(\frac{\sqrt{\varepsilon_{0} / \mu_{0}} \int_{\mathrm{Ze}} \eta_{\mathrm{Ze}}|E|^{2} \alpha_{\mathrm{Ze}} \mathrm{d} A}{\int_{\mathrm{all}}(1 / 2)(E \times \widetilde{H}) \widehat{z} \mathrm{~d} A}\right), \mathrm{cm}^{-1} .
$$

The denominator of equation (3) represents the integral of the Poynting vector, where $H$ stands for the magnetic field strength. $\varepsilon_{0}$ and $\mu_{0}$ stand for the free space permittivity and permeability, respectively. $\eta$ and $\alpha$ represent the RI and absorption coefficient, respectively.

The use of zeonex as a fibre material may introduce a negligible amount of material dispersion [66]. Hence, this dispersion can be avoided, and the only dispersion that needs to be considered is the waveguide dispersion. A PCF with flat dispersion facilitates the examination of the capability of the fibre to inherit multichannel signals. Therefore, the quality of signal propagation from the source to the sink can be evaluated through this parameter. The dispersion (D) for the proposed BCS is estimated using the following equation $[67,68]$ :

$$
D=\frac{2}{c} \frac{\mathrm{d} \eta_{\mathrm{eff}}}{\mathrm{d} \omega}+\frac{\omega}{c} \frac{\mathrm{d}^{2} \eta_{\mathrm{eff}}}{\mathrm{d} \omega^{2}}, \mathrm{ps} / \mathrm{THz} / \mathrm{cm},
$$

where $\omega$ and $\eta_{\text {eff }}$ represent the angular frequency and the effective RI, respectively.

Another key parameter that has an impact on the sensing performance is the CL. This loss results from improper PCF structure and the leaky nature of the mode. Hence, a proper PCF model can result in a reduced CL value. The amount of $\mathrm{CL}$ is quantified using the following equation:

$$
\mathrm{CL}=\left(\frac{4 \pi f}{c}\right) \times \operatorname{Im}\left(\eta_{\mathrm{eff}}\right), \mathrm{cm}^{-1} \text {. }
$$

The most important optical parameter that directly computes the sensing performance of any PCF-based sensor is the relative sensitivity (RS). This parameter is directly proportional to the power fraction $\left(P_{f}\right)$, which quantifies the amount of light power present in the core compared with the entire injected power. The relative sensitivity for the proposed BCS is calculated using 


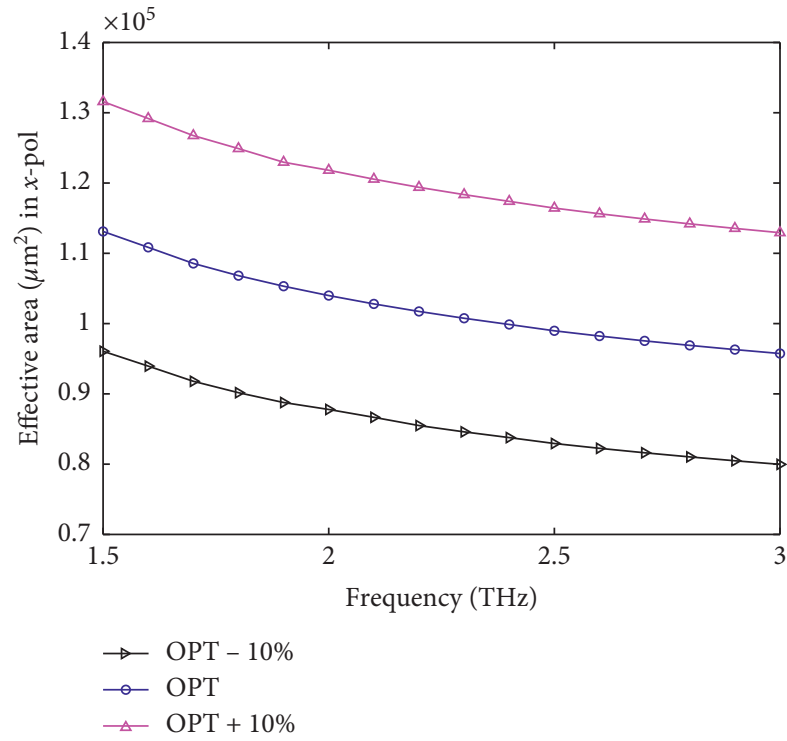

(a)

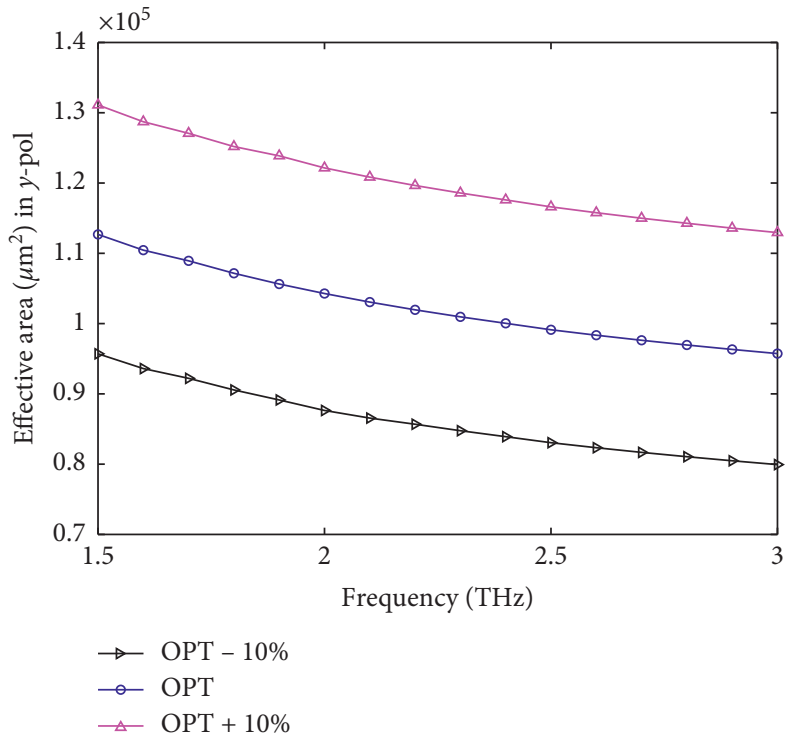

(b)

Figure 3: Comparison of the EAs for the three models in the THz band. (a) $x$-PoM and (b) $y$-PoM.

$\mathrm{RS}=\frac{P_{f} \times \eta_{a}}{\eta_{\text {eff }}}=\frac{\int_{a} \operatorname{Re}\left(E_{x} H_{y}-H_{x} E_{y}\right) \mathrm{d} x \mathrm{~d} y}{\int_{\text {all }} \operatorname{Re}\left(E_{x} H_{y}-H_{x} E_{y}\right) \mathrm{d} x \mathrm{~d} y} \times\left(\eta_{a} / \eta_{\text {eff }}\right), \%$,

where $\eta_{a}$ denotes the RI of the analyte.

\section{Simulation Results}

Different types of analytes or target samples are injected into the core region of the sensor separately and once at a time. Then, the light propagation through the core region of the proposed BCS provides us with different values for the optical parameters for different types of analytes.

5.1. Optimum Model Selection. To validate the selection of the OPT model as the BCS in this paper, we have first carried out the values of the optical parameters for the OPT $-10 \%$, $\mathrm{OPT}$, and $\mathrm{OPT}+10 \%$ models. We have performed this simulation for the analyte with $1.44 \mathrm{RI}$.

The values of EffA in $x$ - and $y$-PoM for the three models in the THz band are shown in Figures 3(a) and 3(b), respectively. Since EffA is a measure of how light is spread inside the PCF, the lower values for it is desirable. The lowest value of it is attained for the OPT $-10 \%$ model, whereas the highest value is found for the OPT $+10 \%$ model. The curve for the EffA for the OPT model lies between the other two models. The OPT model exhibits $98975 \mu \mathrm{m}^{2}$ and $99121 \mu \mathrm{m}^{2}$ in $x$ - and $y$-PoM, respectively, at $2.5 \mathrm{THz}$.

The NA indicates the efficiency of a PCF in collecting light. A higher value of NA is expected for every PCF-based chemical sensor. Figure 4 depicts the values of NA in the $\mathrm{THz}$ band for the three models. The OPT $-10 \%$ model shows the highest NA, while the OPT attains a NA of 0.2104 at $2.5 \mathrm{THz}$.

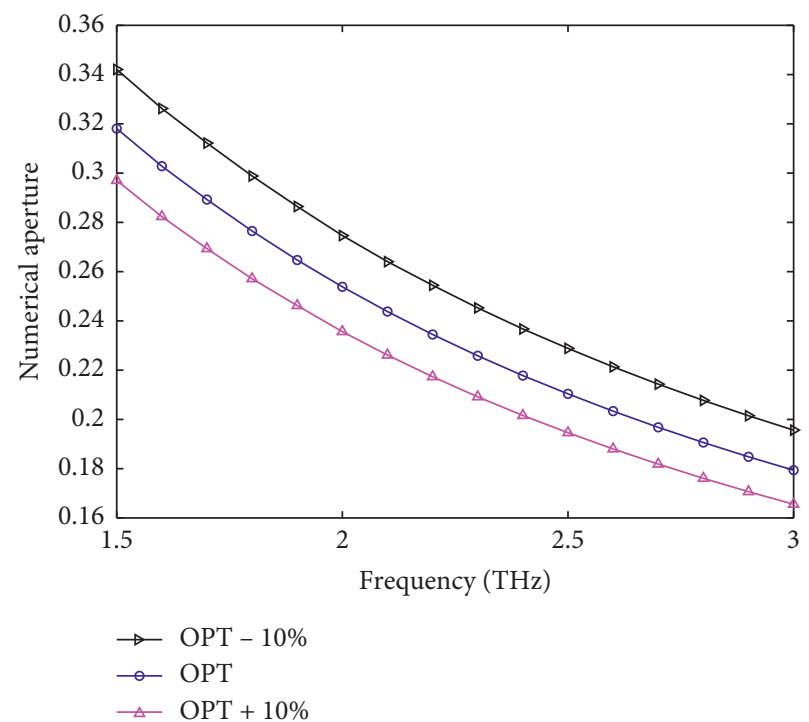

FIGURE 4: Representation of the numerical apertures for the three models in the $\mathrm{THz}$ band.

The EML in $x$ - and $y$-PoM are presented in Figures 5(a) and $5(\mathrm{~b})$ separately. In the case of $x$-polarization, the OPT $-10 \%$ model has the lowest EML of about $0.0058 \mathrm{~cm}^{-1}$ at $2.5 \mathrm{THz}$. Again, the OPT $-10 \%$ model shows the lowest EML of about $0.0057 \mathrm{~cm}^{-1}$ at $2.5 \mathrm{THz}$ in $y$-PoM. However, the OPT model has an EML of only $0.0060 \mathrm{~cm}^{-1}$ and $0.0058 \mathrm{~cm}^{-1}$ in the $x$ - and $y$-polarization mode, respectively, at the same point which is very close to the lowest value.

Figure 6 represents the dispersion for the three models in the THz band. All three models show low dispersion, but the OPT and OPT $+10 \%$ model show lower dispersion compared with the OPT $-10 \%$ model. However, all three models exhibit nearly flat dispersion in the frequency band ranging 


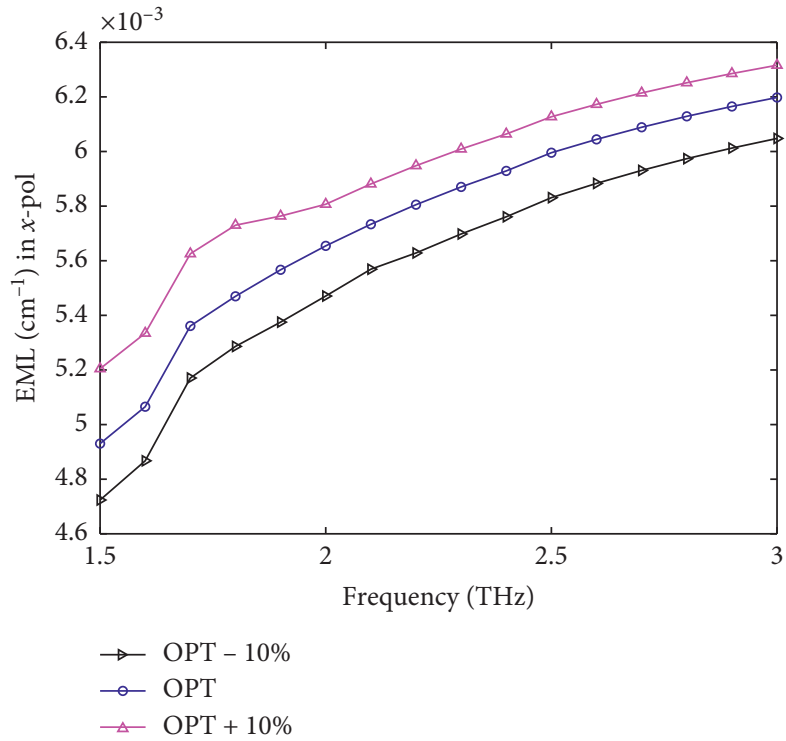

(a)

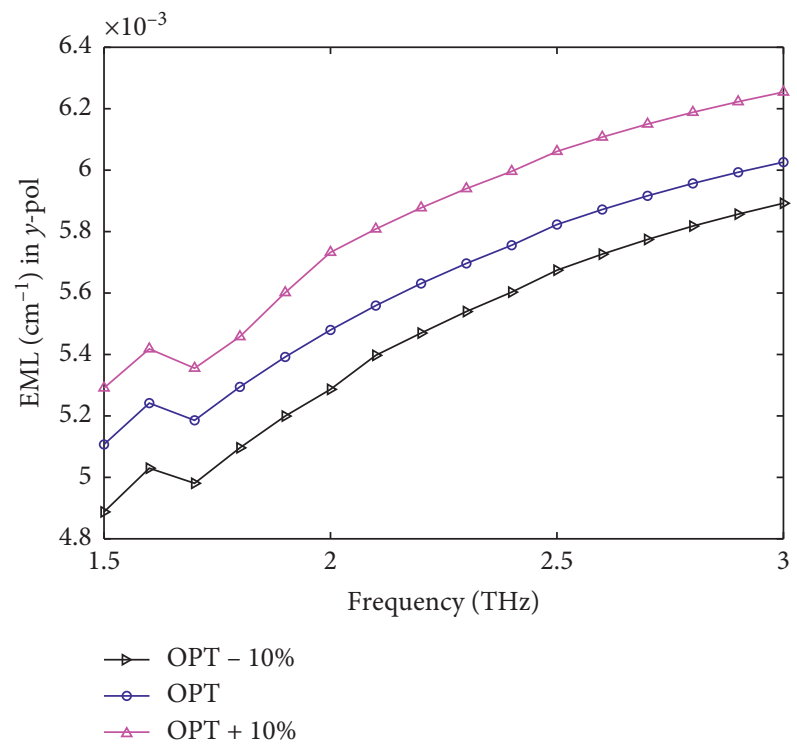

(b)

FIgURE 5: Comparison of the EML for the three models as a function of the THz band. (a) $x$-PoM and (b) $y$-PoM.

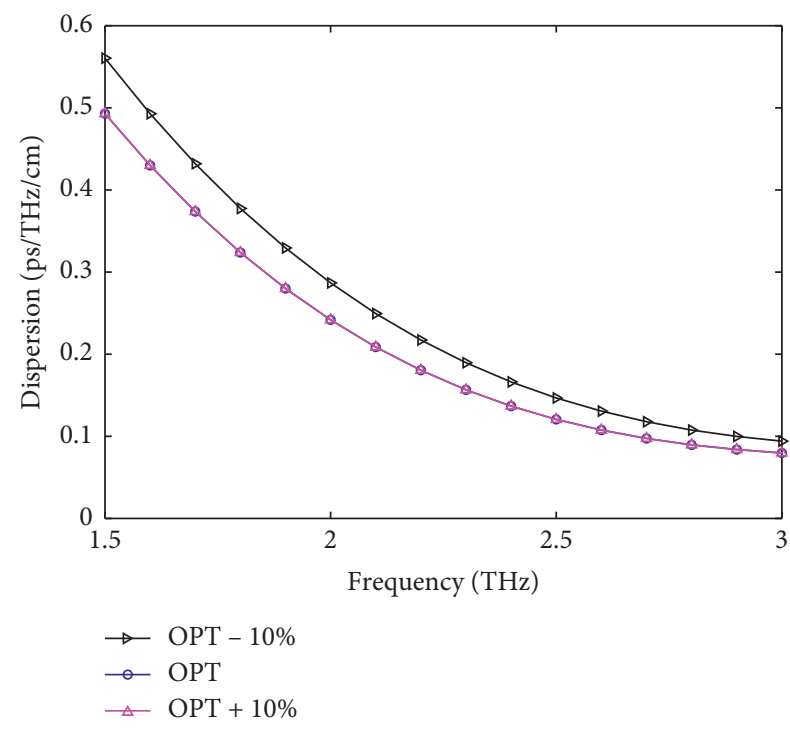

Figure 6: Representation of the dispersion for the three models in the $\mathrm{THz}$ band.

from 2.4 to $3.0 \mathrm{THz}$. The values of dispersions are $0.1467 \pm 0.0129, \quad 0.1206 \pm 0.0116$, and $0.1206 \pm 0.0116 \mathrm{ps} /$ $\mathrm{THz} / \mathrm{cm}$ in these frequency range for OPT $-10 \%$, OPT, and OPT $+10 \%$ model, respectively.

The CL in $x$ - and $y$-PoM for the three models are presented in Figures 7(a) and 7(b), respectively. All the models show ultra-low $\mathrm{CL}$ in the $\mathrm{THz}$ band. The lowest values in both $x$ - and $y$-PoM are attained for the OPT model at $2.5 \mathrm{THz}$. The numerical values of CL for the OPT model in $x$ and $y$-PoM are $3.20 \times 10^{-12}$ and $9.00 \times 10^{-12} \mathrm{~cm}^{-1}$ at $2.5 \mathrm{THz}$.

Figures $8(\mathrm{a})$ and $8(\mathrm{~b})$ are the representation of the relative sensitivity for the three models in $x$ - and $y$-PoM. The OPT $+10 \%$ model exhibits dominant relative sensitivity in both $x$ - and $y$-PoM compared with the other two models since relative sensitivity is a function of the core power fraction, which is higher for this model. The values of relative sensitivity attained at $2.5 \mathrm{THz}$ for the OPT $+10 \%$ model are 95.99 and $95.94 \%$, respectively. On the other hand, the OPT model attains 95.20 and $95.13 \%$ relative sensitivity in $x$ - and $y$-PoM, respectively, at the same frequency.

Table 2 represents the numerical values of the optical parameters for the three models. The optimum values are marked in italics. This italic marking shows that none of the three models is dominant for all the parameters. Considering a trade-off among the optical parameters, the OPT model has been chosen as the BCS in this paper. The OPT model maintains a balance between the losses and relative sensitivities. To attain higher power fraction, relative sensitivity, and NA as well as lower EML, EA, dispersion, and CL are the key objectives for any type of PCF-based sensors. As no particular model among the OPT-10\%, OPT, and OPT $+10 \%$ model has attained standard values for all the parameters at the same time, we have to select a model that has nearly attained typical values for the parameters. Hence, we have selected the OPT model as the BCS in this study.

5.2. Optimum Strut Selection. To evaluate the optimum value of strut for our BCS, we have varied the values of it and evaluated the optical parameters for each time. We have simulated the OPT model for three values of strut, i.e., $7.5 \mu \mathrm{m}, 10 \mu \mathrm{m}$, and $12.5 \mu \mathrm{m}$. We have performed this simulation for the analyte with 1.44 RI.

Figures 9(a) and 9(b) show the value of EffA in the THz band in $x$ - and $y$-PoM, respectively, for three dissimilar values of the strut. The $7.5 \mu \mathrm{m}$ strut model has the lowest value for EffA at $2.5 \mathrm{THz}$ in both $x$ - and $y$-PoM. The values of EffA for the $10 \mu \mathrm{m}$ strut model in $x$ - and $y$-PoM are between the values of EffA for the other two models. 


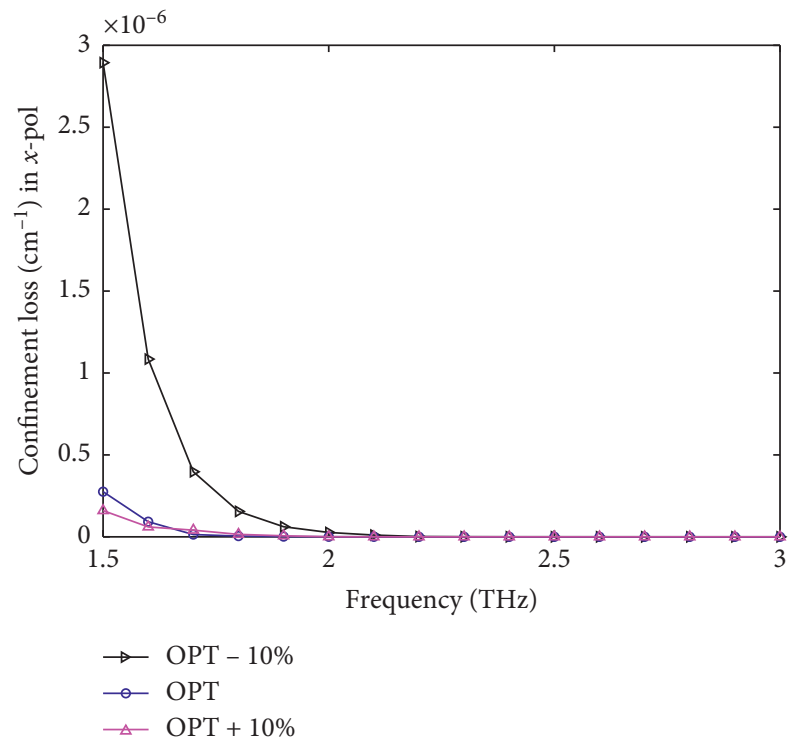

(a)

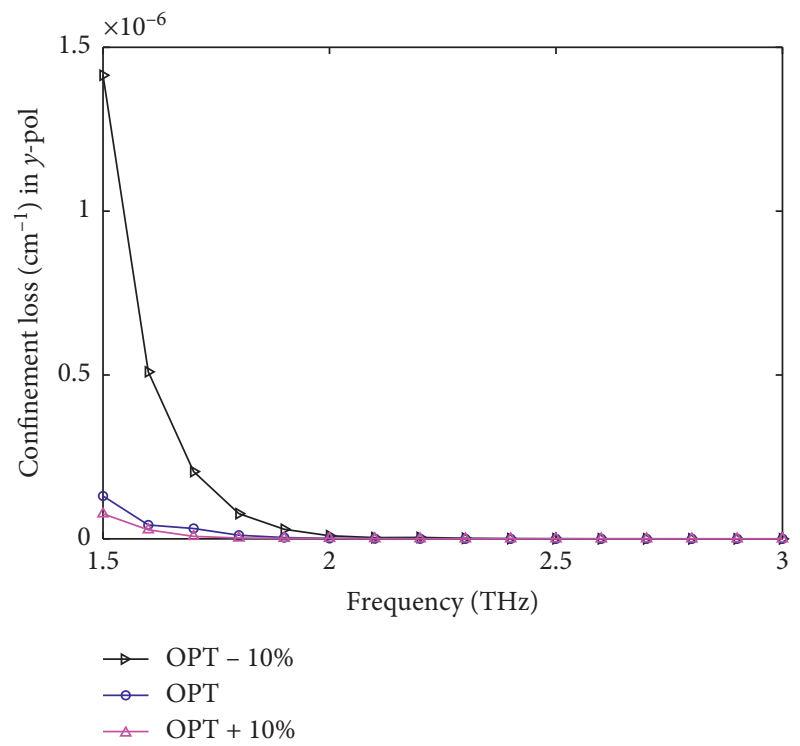

(b)

FIgURE 7: Representation of the CL for the three models in the THz band. (a) $x$-PoM and (b) $y$-PoM.

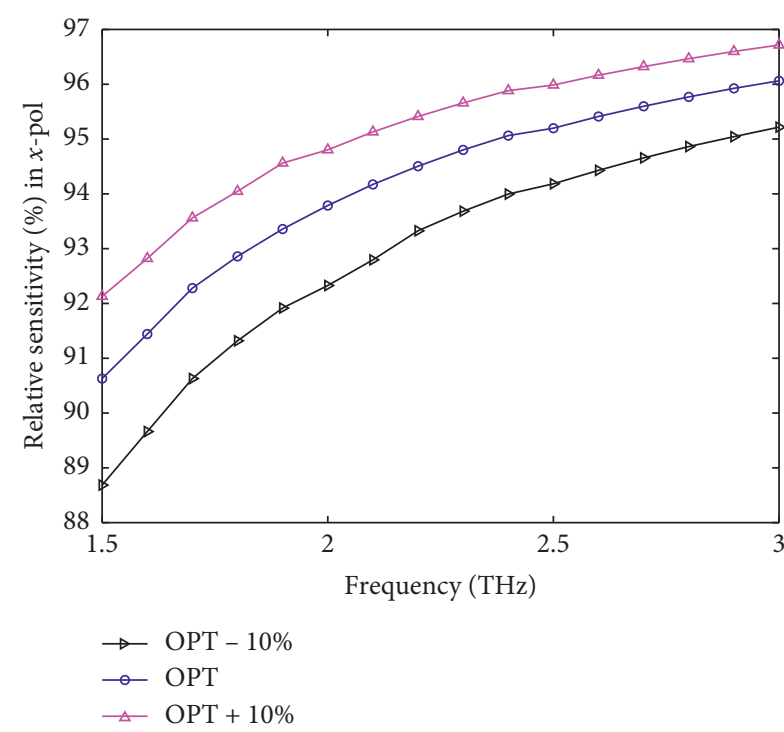

(a)

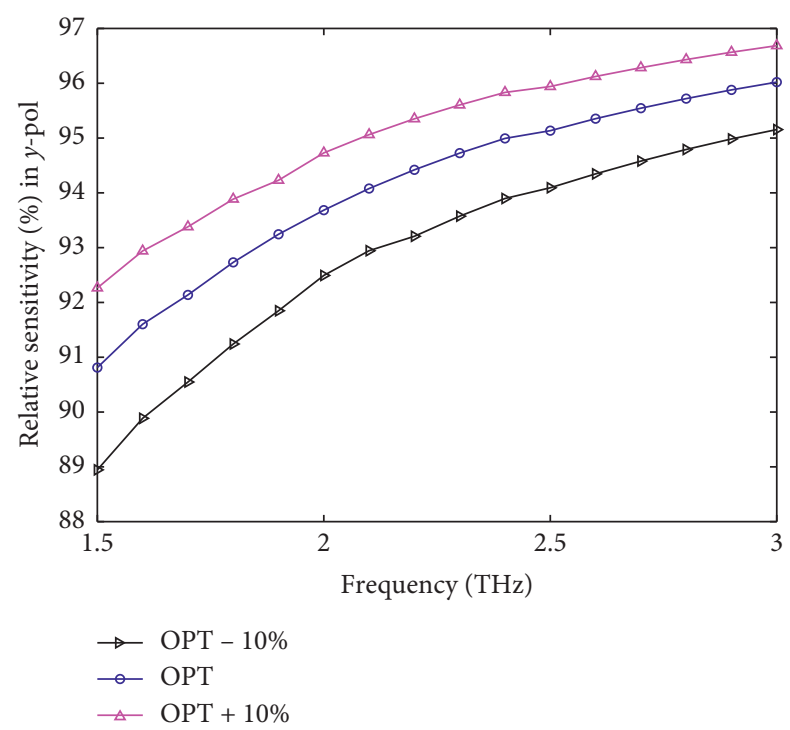

(b)

Figure 8: Depiction of the relative sensitivity for the three models as a function of the THz band. (a) $x$-PoM and (b) $y$-PoM.

TABle 2: Comparison of the optical parameters for the three model sat $2.5 \mathrm{THz}$.

\begin{tabular}{|c|c|c|c|c|c|c|c|c|c|c|}
\hline Model & $\begin{array}{l}\text { EffA }_{X} \\
\left(\mu \mathrm{m}^{2}\right) \\
\end{array}$ & $\begin{array}{l}\text { EffA }_{Y} \\
\left(\mu \mathrm{m}^{2}\right)\end{array}$ & NA & $\begin{array}{l}\mathrm{EML}_{X} \\
\left(\mathrm{~cm}^{-1}\right)\end{array}$ & $\begin{array}{l}\mathrm{EML}_{Y} \\
\left(\mathrm{~cm}^{-1}\right)\end{array}$ & $\begin{array}{c}\text { Dispersion } \\
\text { (ps/THz/cm) }\end{array}$ & $\mathrm{CL}_{X}\left(\mathrm{~cm}^{-1}\right)$ & $\mathrm{CL}_{Y}\left(\mathrm{~cm}^{-1}\right)$ & $\begin{array}{l}\mathrm{RS}_{X} \\
(\%)\end{array}$ & $\mathrm{RS}_{Y}(\%)$ \\
\hline & 82939 & 83051 & & 0.0058 & 0.0057 & $0.1467 \pm 0.0129$ & $1.13 \times 10^{-10}$ & $3.11 \times 10^{-10}$ & 94.18 & 94.09 \\
\hline OPT & 98975 & 99121 & & 0.0060 & 0.0058 & $0.1206 \pm 0.0116$ & $3.20 \times 10^{-12}$ & $9.00 \times 10^{-12}$ & 95.20 & 95.13 \\
\hline $\mathrm{OPT}+10 \%$ & 116435 & 116610 & 0.1946 & 0.0061 & 0.0061 & $0.1206 \pm 0.0116$ & $5.00 \times 10^{-12}$ & $1.38 \times 10^{-11}$ & 95.99 & 95.95 \\
\hline
\end{tabular}




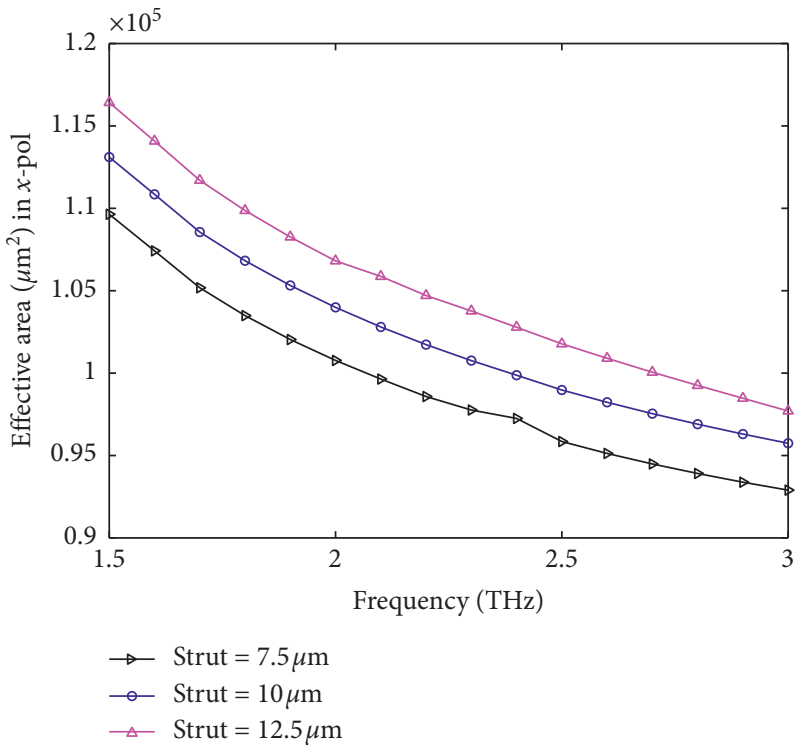

(a)

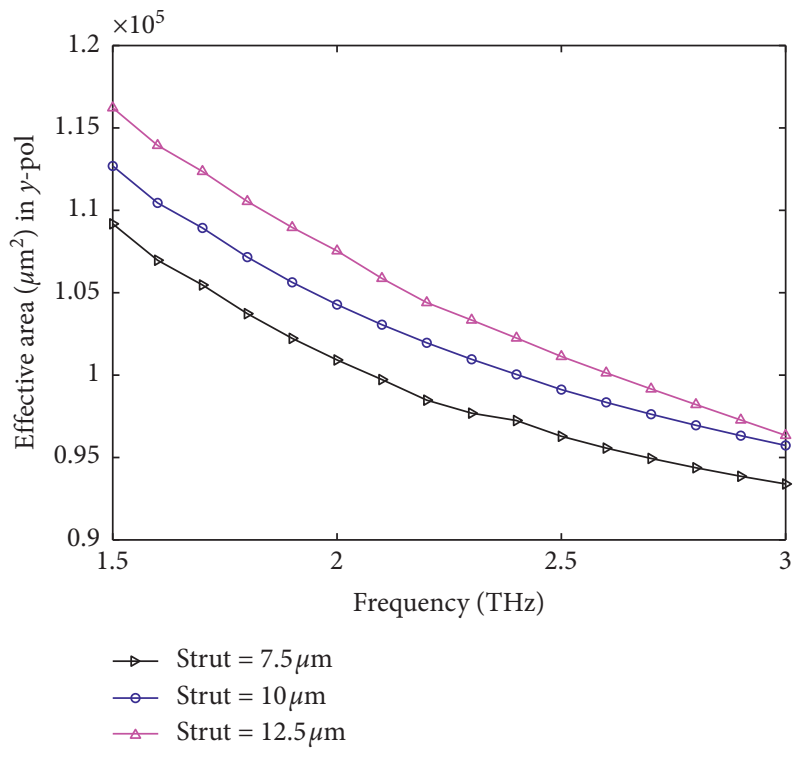

(b)

Figure 9: Representation of the EAs for the three models with different strut values in the THz band. (a) $x$-PoM and (b) $y$-PoM.

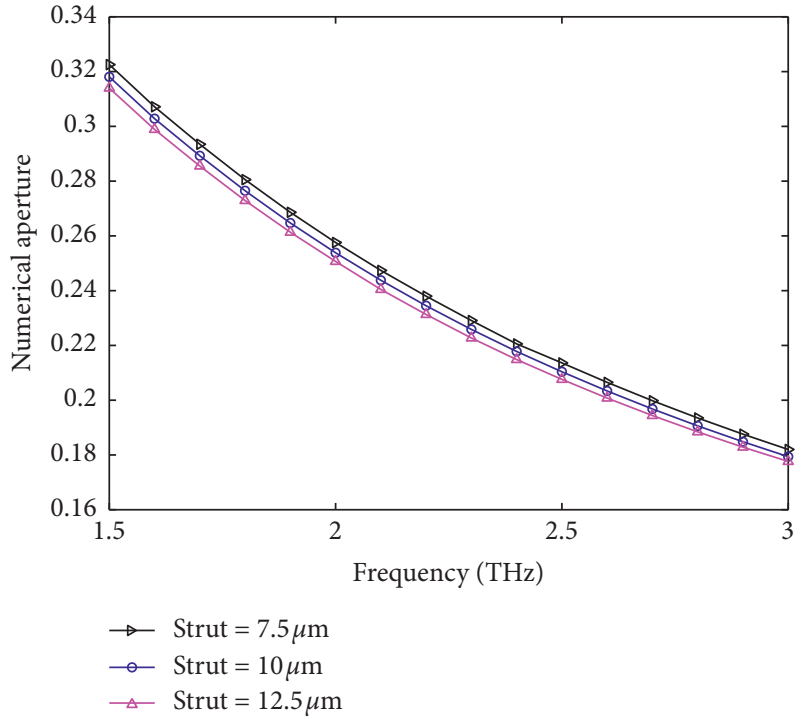

FIgURE 10: Depiction of the numerical apertures in the $\mathrm{THz}$ band for the three dissimilar struts.

The values of the NA in the THz band for the $7.5 \mu \mathrm{m}$, $10 \mu \mathrm{m}$, and $12.5 \mu \mathrm{m}$ strut models are shown in Figure 10. All three models show nearly equal values for the NA. However, the $7.5 \mu \mathrm{m}$ strut model shows the highest value of 0.2136 for the NA at $2.5 \mathrm{THz}$. The value of NA for the $10 \mu \mathrm{m}$ strut model is close to the maximum $\mathrm{NA}$ in the $\mathrm{THz}$ regime.

Figures 11(a) and 11(b) show the values of EML in $x$ - and $y$-PoM, respectively, for the three models. The $12.5 \mu \mathrm{m}$ strut model shows the lowest values for EML in both the $x$ - and $y$ PoM. These values are 0.0059 and $0.00576 \mathrm{~cm}^{-1}$ at $2.5 \mathrm{THz}$ in $x$ - and $y$-PoM, respectively, whereas the $10 \mu \mathrm{m}$ strut model has 0.0060 and $0.0058 \mathrm{~cm}^{-1}$ at the same frequency.

The amount of dispersion in the THz band for the three models with different strut values is shown in Figure 12. All these models show nearly flat dispersion from 2.4 to $3.0 \mathrm{THz}$. The $10 \mu \mathrm{m}$ strut model exhibits the lowest dispersion at $2.5 \mathrm{THz}$. The values of dispersion are $0.1223 \pm 0.0121$, $0.1206 \pm 0.0116$, and $0.1206 \pm 0.0116 \mathrm{ps} / \mathrm{THz} / \mathrm{cm}$ for $7.5 \mu \mathrm{m}$, $10 \mu \mathrm{m}$, and $12.5 \mu \mathrm{m}$ strut models, respectively.

The fluctuation of CL in the $x$ - and $y$-PoM due to the variation in strut values is revealed in Figures 13(a) and 13(b), respectively. In both PoMs, the CL decreases sharply with the rise in frequency. Though the CL for the $12.5 \mu \mathrm{m}$ strut model is the lowest initially, the $7.5 \mu \mathrm{m}$ strut model has the lowest $\mathrm{CL}$ at $2.5 \mathrm{THz}$. The amount of the $\mathrm{CL}$ approach nearly zero immediately after $2.0 \mathrm{THz}$ for the three models. However, the $10 \mu \mathrm{m}$ strut model confirms a lower value of $\mathrm{CL}$ in both PoMs at $2.5 \mathrm{THz}$. The values of CL for the $7.5 \mu \mathrm{m}$ strut model are $2.66 \times 10^{-13}$ and $7.16 \times 10^{-12} \mathrm{~cm}^{-1}$ in the $x$ and $y$-PoM, respectively, at $2.5 \mathrm{THz}$. Both these values are very close to the respective values of CL for the $10 \mu \mathrm{m}$ strut model.

Figures 14(a) and 14(b) depict the values of relative sensitivity as a function of the $\mathrm{THz}$ band for the $7.5 \mu \mathrm{m}$, $10 \mu \mathrm{m}$, and $12.5 \mu \mathrm{m}$ strut models in $x$ - and $y$-PoM, respectively. The $7.5 \mu \mathrm{m}$ strut model shows the highest relative sensitivity for both PoMs throughout the THz band. This model has attained $96.00 \%$ and $95.96 \%$ relative sensitivity at $2.5 \mathrm{THz}$ for the $x$ - and $y$-PoM, respectively. On the other hand, the $10 \mu \mathrm{m}$ strut model shows higher relative sensitivity in both $x$ - and $y$-PoM compared with the $12.5 \mu \mathrm{m}$ strut model. 


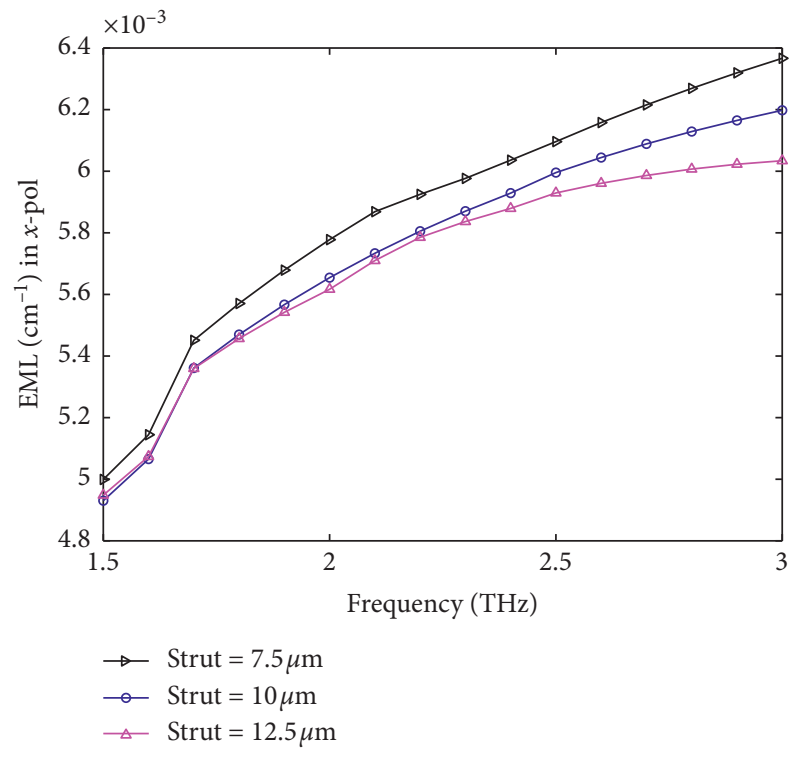

(a)

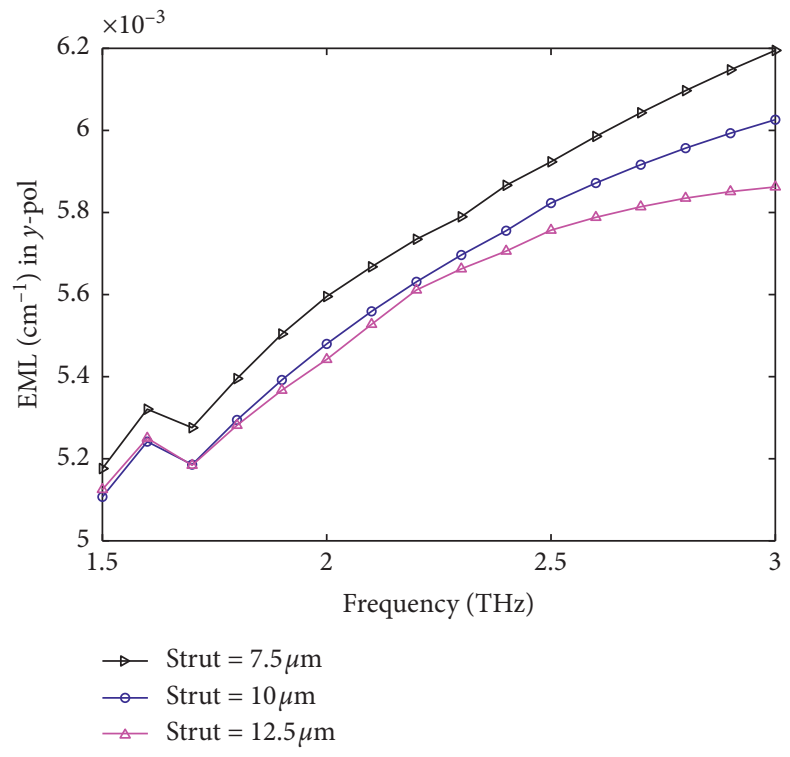

(b)

Figure 11: Representation of the EML in the THz band for the three different strut values. (a) $x$-PoM and (b) $y$-PoM.

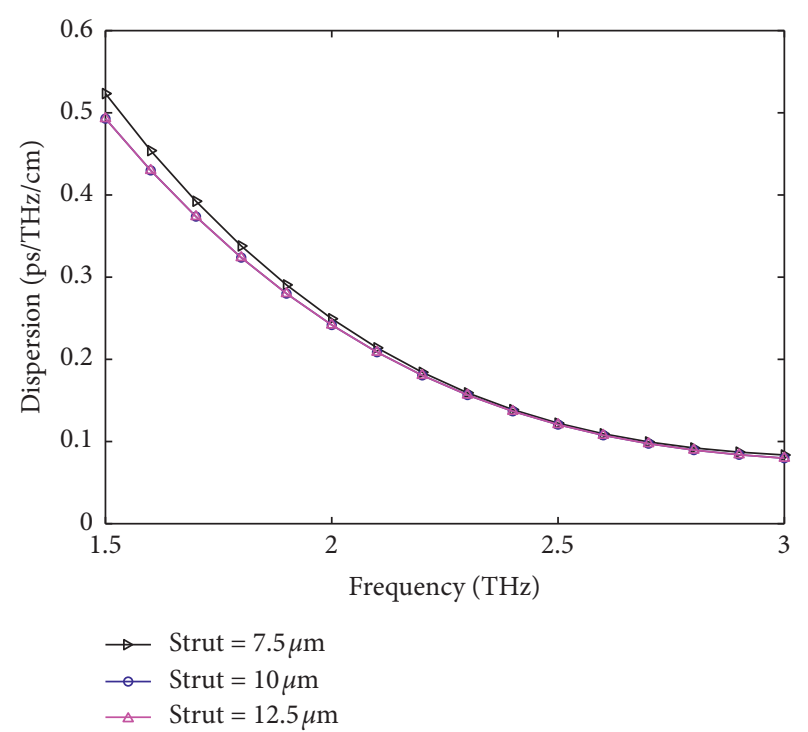

Figure 12: Representation of the dispersion in the $\mathrm{THz}$ band for the three strut values.

A numerical comparison among the values of optical parameters for the $7.5 \mu \mathrm{m}, 10 \mu \mathrm{m}$, and $12.5 \mu \mathrm{m}$ strut models is shown in Table 3. The standard values attained for each optical parameter are marked in italics. The table reflects that the $7.5 \mu \mathrm{m}$ strut model has typical values for the optical parameters except for the EML and dispersion. On the other hand, the $10 \mu \mathrm{m}$ strut model has attained nearly typical values for all the optical parameters maintaining lower losses and higher relative sensitivity. Accounting for this scenario, we have selected the $10 \mu \mathrm{m}$ strut model in this paper as it balances among the optical parameters through maintaining comparatively lower loss along with higher relative sensitivity.

5.3. RI-Based Analyte Sensing. The optimum PCF structure and the optimum value for the strut have together modelled the proposed BCS of this paper. This sensor is then used to sense different chemicals with different RI. Injecting any particular chemical into the core region of the sensor, the optical parameters have been evaluated for that chemical using the finer mesh analysis. This strategy is repeated several times to evaluate the optical parameters for the chemicals with different RI values ranging from 1.33 to 1.48.

Figures 15(a) and 15(b) describe the effective sensing region in the THz band for the OPT model in $x$ - and $y$-PoM, respectively. For both PoM, the value of EffA decreases with an increase in the light frequency. This property of this sensor indicated that the light intensity inside the core is higher for higher frequencies. The values of EffA are 104980, 104310, 103050, 101910, 100850, 99880, 98975, 98130, and $97341 \mu \mathrm{m}^{2}$ for the chemicals with RI $1.33,1.34,1.36,1.38$, $1.40,1.42,1.44,1.46$, and 1.48 , respectively, at $2.5 \mathrm{THz}$.

Figure 16 compares the NA of the proposed BCS for chemicals with different RI values. The proposed BCS maintains acceptable values for the NA throughout the $\mathrm{THz}$ band. The values of NA are 0.2045, 0.2052, 0.2064, 0.2075, $0.2085,0.2095,0.2104,0.2112$, and 0.2121 for the chemicals with RI 1.33, 1.34, 1.36, 1.38, 1.40, 1.42, 1.44, 1.46, and 1.48, respectively, at $2.5 \mathrm{THz}$.

The values of EML in the $x$ and $y$-PoM for analytes with dissimilar RI are revealed in Figures 17(a) and 17(b) individually. The proposed model maintains low EML for both PoM. The model shows 0.0051, 0.0052, 0.0054, 0.0056, $0.0057,0.0059,0.0060,0.0061$, and $0.0062 \mathrm{~cm}^{-1} \mathrm{EML}$ for the 


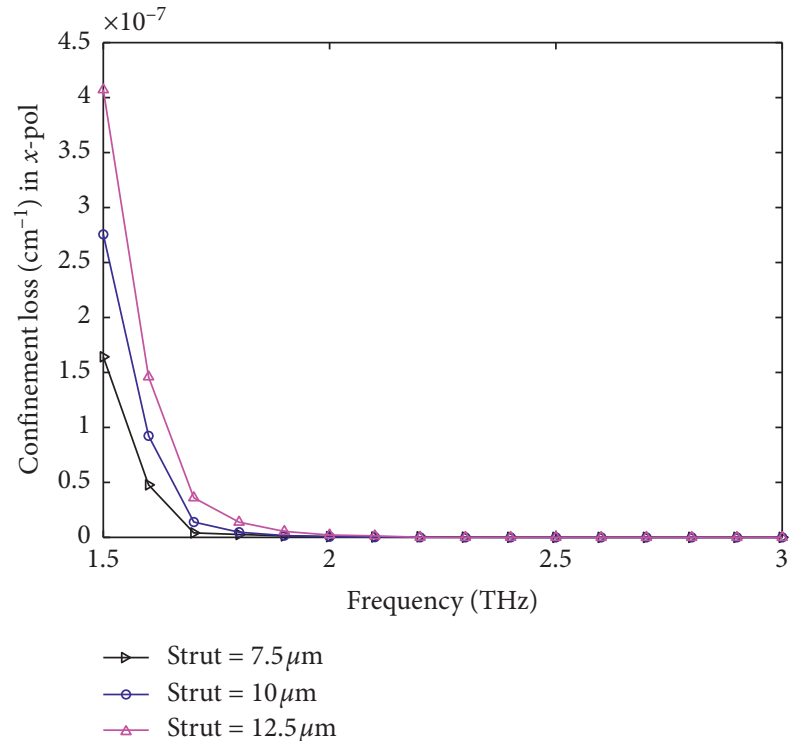

(a)

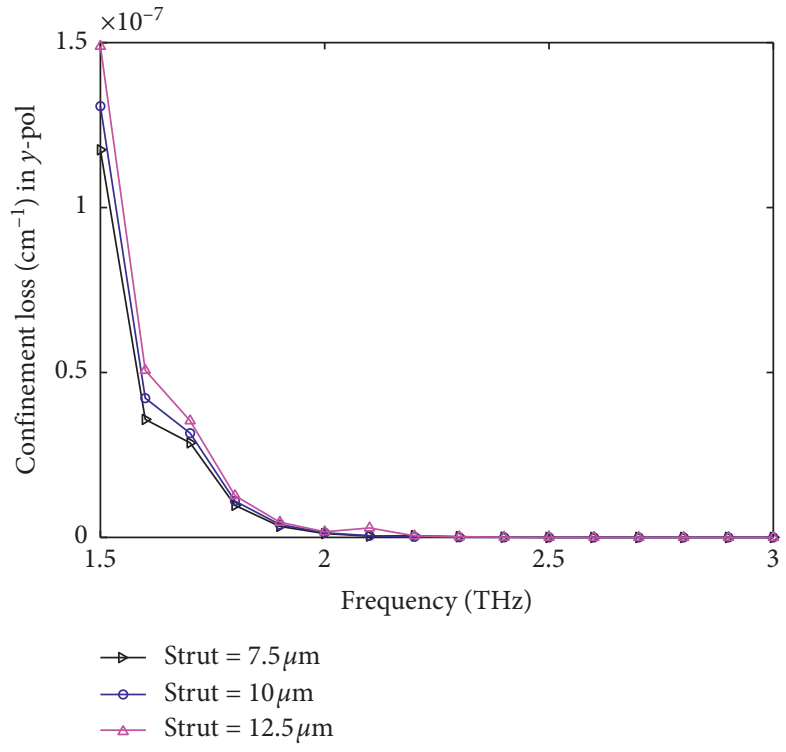

(b)

Figure 13: The fluctuation of the CL in the THz band for the three strut values. (a) $x$-PoM and (b) $y$-PoM.

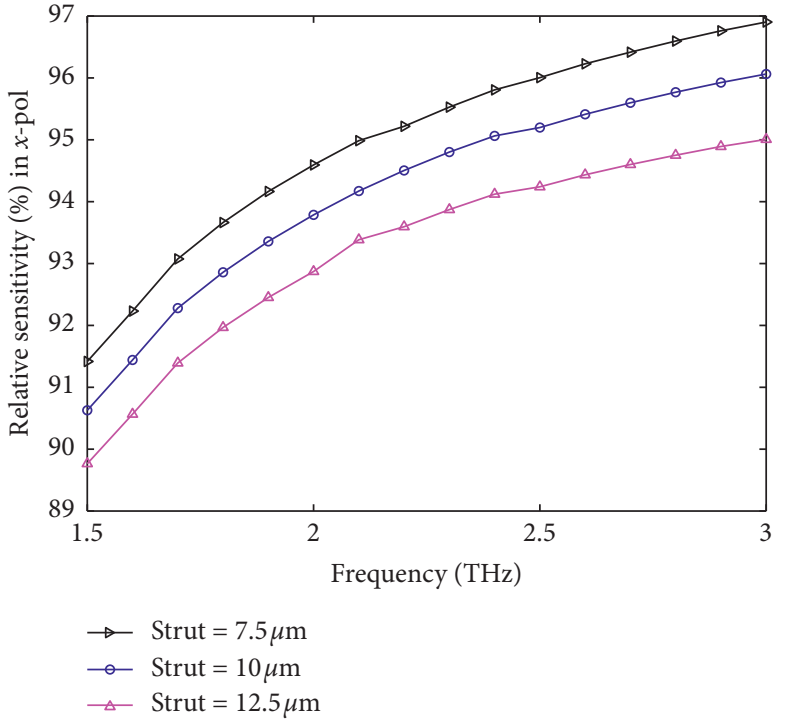

(a)

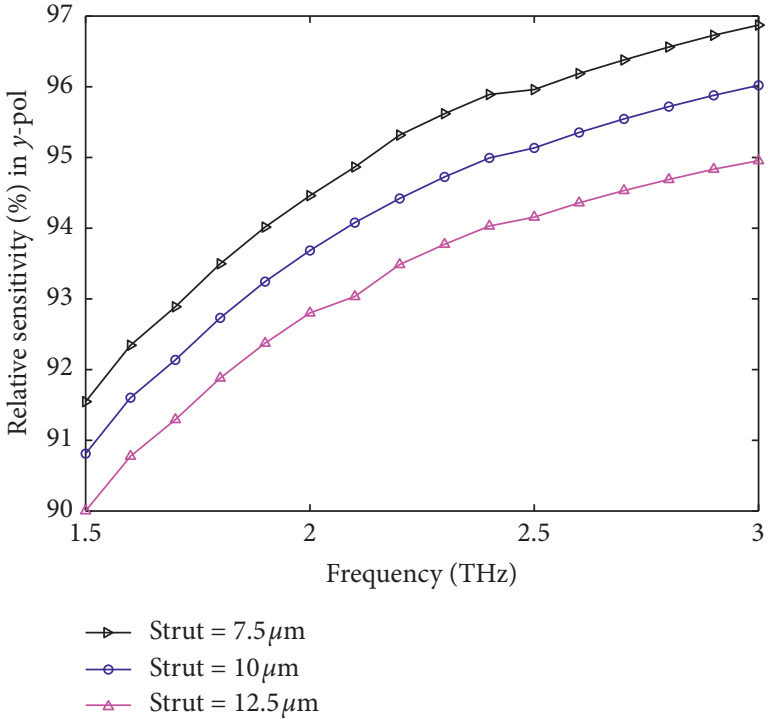

(b)

FIGURE 14: Representation of the relative sensitivity for the three models as a function of the THz band. (a) $x$-PoM and (b) $y$-PoM.

analytes with $1.33,1.34,1.36,1.38,1.40,1.42,1.44,1.46$, and $1.48 \mathrm{RI}$ respectively at $2.5 \mathrm{THz}$ in the $x$-PoM.

Figure 18 compares the dispersion of the proposed BCS for different analytes in the $\mathrm{THz}$ band. The model maintains ultra-low dispersion for all the analytes. Besides, the model exhibits nearly flat dispersion for the frequency band ranging from 2.4 to $3.0 \mathrm{THz}$. The values of dispersion found at $2.5 \mathrm{THz}$ are $0.1185 \pm 0.01225,0.1185 \pm 0.0123,0.1201 \pm$ $0.0127,0.1212 \pm 0.0129,0.1215 \pm 0.01325,0.1184 \pm 0.01215$, $0.1206 \pm 0.0116, \quad 0.1176 \pm 0.0112, \quad 0.122 \pm 0.0131$ for the analytes with $1.33,1.34,1.36,1.38,1.40,1.42,1.44,1.46$, and 1.48 RI respectively.

The comparison of CL of the proposed BCS in the $x$-and $y$-PoM for different analytes are pictured in Figures 19(a) and 19(b), respectively. In both the propagation modes, the $\mathrm{CL}$ approaches absolute zero immediately after $2.0 \mathrm{THz}$. This indicates higher light confinement inside the core of the sensor model. The values of CL are $6.92 \times 10^{-10}, 4.28 \times 10^{-10}$, $1.64 \times 10^{-10}, 6.30 \times 10^{-11}, 2.40 \times 10^{-11}, 8.90 \times 10^{-12}, 3.20 \times$ $10^{-12}, 1.10 \times 10^{-12}$, and $3.00 \times 10^{-13} \mathrm{~cm}^{-1}$ for the analytes 
TABLE 3: Comparison of the optical parameters for the three strut values at $2.5 \mathrm{THz}$.

\begin{tabular}{|c|c|c|c|c|c|c|c|c|c|c|}
\hline $\begin{array}{l}\text { Strut } \\
(\mu \mathrm{m})\end{array}$ & $\begin{array}{l}\text { EffA }_{X} \\
\left(\mu \mathrm{m}^{2}\right)\end{array}$ & $\begin{array}{l}\text { EffA }_{Y} \\
\left(\mu \mathrm{m}^{2}\right)\end{array}$ & NA & $\begin{array}{l}\mathrm{EML}_{X} \\
\left(\mathrm{~cm}^{-1}\right)\end{array}$ & $\begin{array}{l}\mathrm{EML}_{Y} \\
\left(\mathrm{~cm}^{-1}\right)\end{array}$ & $\begin{array}{c}\text { Dispersion } \\
(\mathrm{ps} / \mathrm{THz} / \mathrm{cm})\end{array}$ & $\mathrm{CL}_{X}\left(\mathrm{~cm}^{-1}\right)$ & $\mathrm{CL}_{Y}\left(\mathrm{~cm}^{-1}\right)$ & $\begin{array}{l}\mathrm{RS}_{X} \\
(\%)\end{array}$ & $\mathrm{RS}_{Y}(\%)$ \\
\hline 7.5 & 95849 & 96289 & 0.2136 & 0.0061 & 0.0059 & $0.1223 \pm 0.0121$ & $2.66 \times 10^{-13}$ & $7.16 \times 10^{-12}$ & 96.00 & 95.96 \\
\hline 10 & 98975 & 99121 & 0.2104 & 0.0060 & 0.0058 & $0.1206 \pm 0.0116$ & ${ }_{12}^{3.20 \times 10^{-}}$ & $\underset{12}{9.00 \times 10^{-}}$ & 95.20 & 95.13 \\
\hline 12.5 & 101775 & 101131 & 0.2076 & 0.0059 & 0.00576 & $0.1206 \pm 0.0116$ & $7.93 \times 10^{-12}$ & $3.17 \times 10^{-11}$ & 94.24 & 94.16 \\
\hline
\end{tabular}
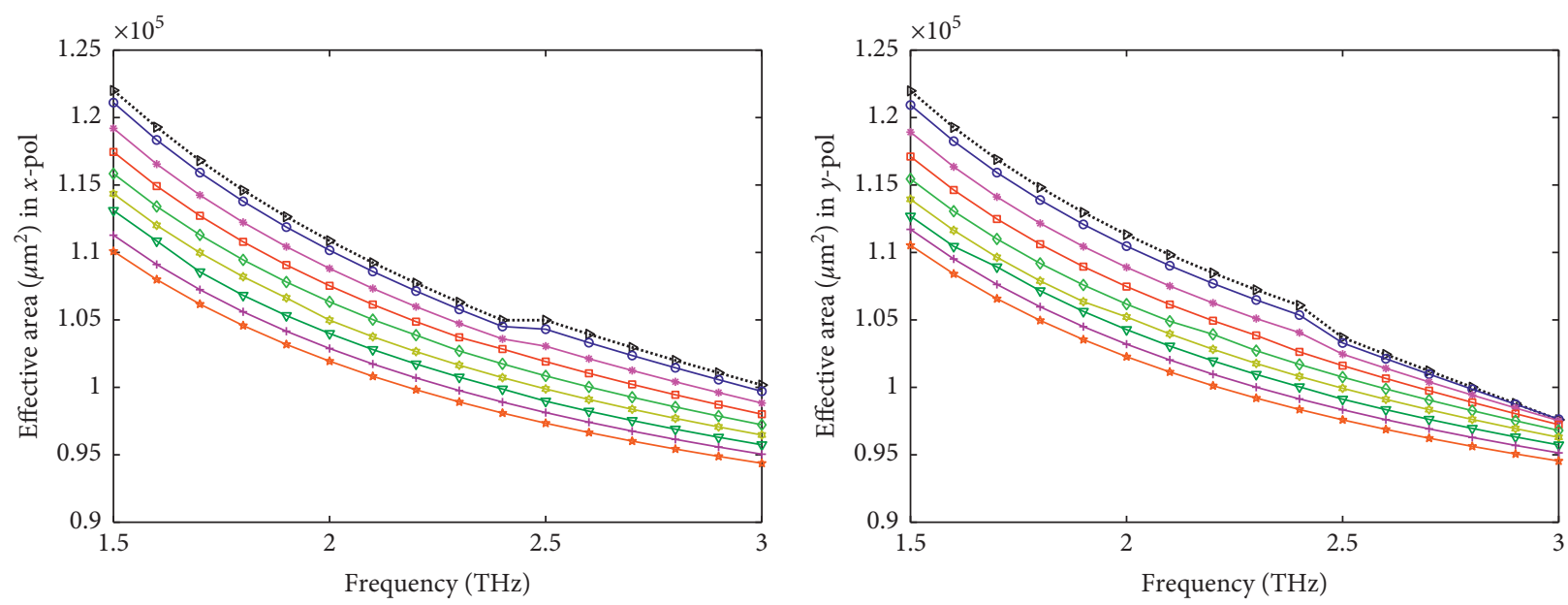

$$
\begin{array}{ll}
\rightarrow \text { RI }=1.33 & \rightarrow \mathrm{RI}=1.42 \\
\rightarrow \mathrm{RI}=1.34 & \rightarrow \mathrm{RI}=1.44 \\
\rightarrow \mathrm{RI}=1.36 & \rightarrow \mathrm{RI}=1.46 \\
\rightarrow \mathrm{RI}=1.38 & \rightarrow \mathrm{RI}=1.48 \\
\rightarrow \mathrm{RI}=1.40 &
\end{array}
$$

(a)

$$
\begin{array}{ll}
\because \triangleright . & \mathrm{RI}=1.33 \\
\rightarrow & \mathrm{RI}=1.34 \\
\rightarrow & \mathrm{RI}=1.36 \\
\rightarrow & \mathrm{RI}=1.38 \\
\rightarrow & \mathrm{RI}=1.40
\end{array}
$$

(b)

Figure 15: Comparison of the EAs in the THz band for different analytes with different RI. (a) $x$-PoM and (b) $y$-PoM.

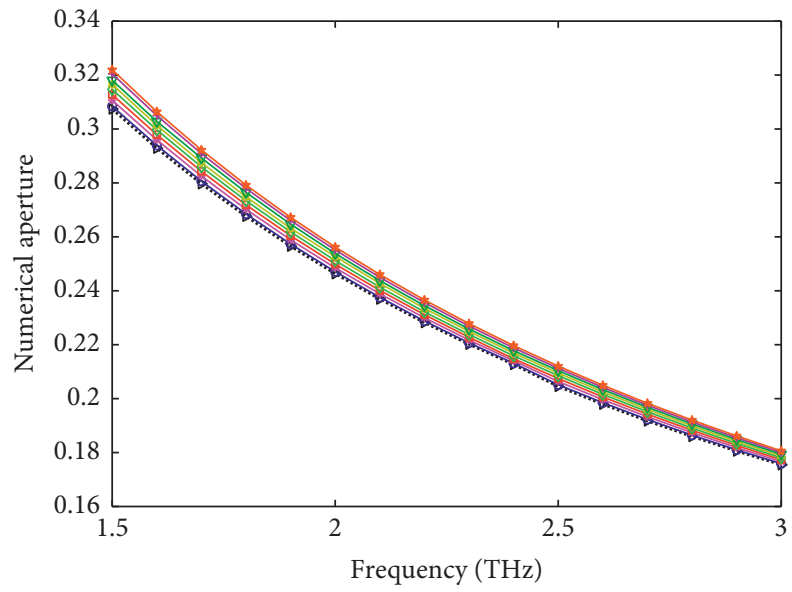

$$
\begin{array}{llrl}
\rightarrow & \mathrm{RI}=1.33 & \rightarrow \mathrm{RI}=1.42 \\
\rightarrow \mathrm{RI}=1.34 & \rightarrow \mathrm{RI}=1.44 \\
\rightarrow \mathrm{RI}=1.36 & \rightarrow \mathrm{RI}=1.46 \\
\rightarrow \mathrm{RI}=1.38 & \rightarrow \mathrm{RI}=1.48 \\
\rightarrow \mathrm{RI}=1.40 &
\end{array}
$$

FiguRE 16: Representation of the numerical apertures in the THz band for different RI. 


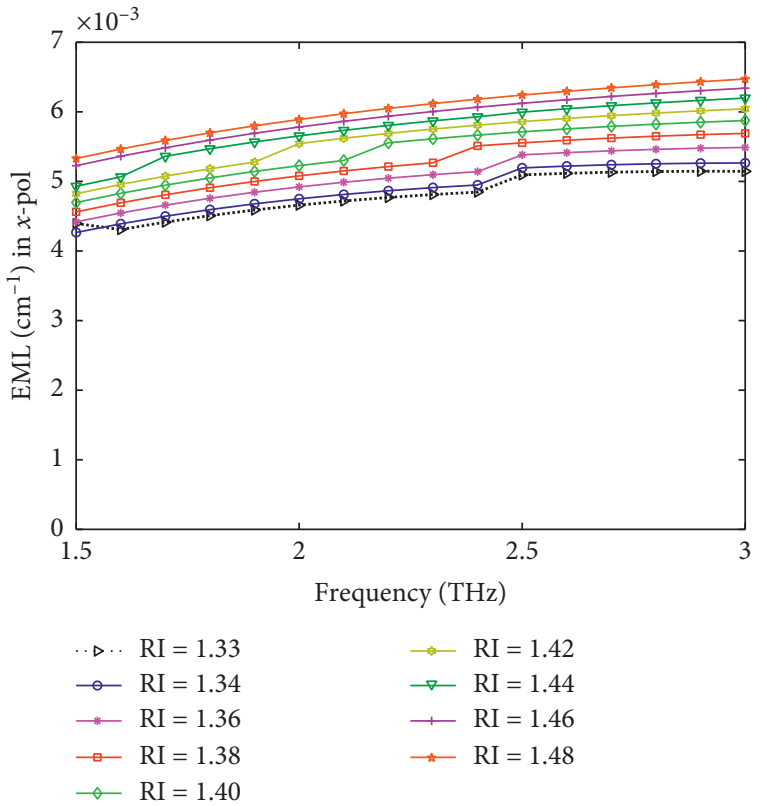

(a)

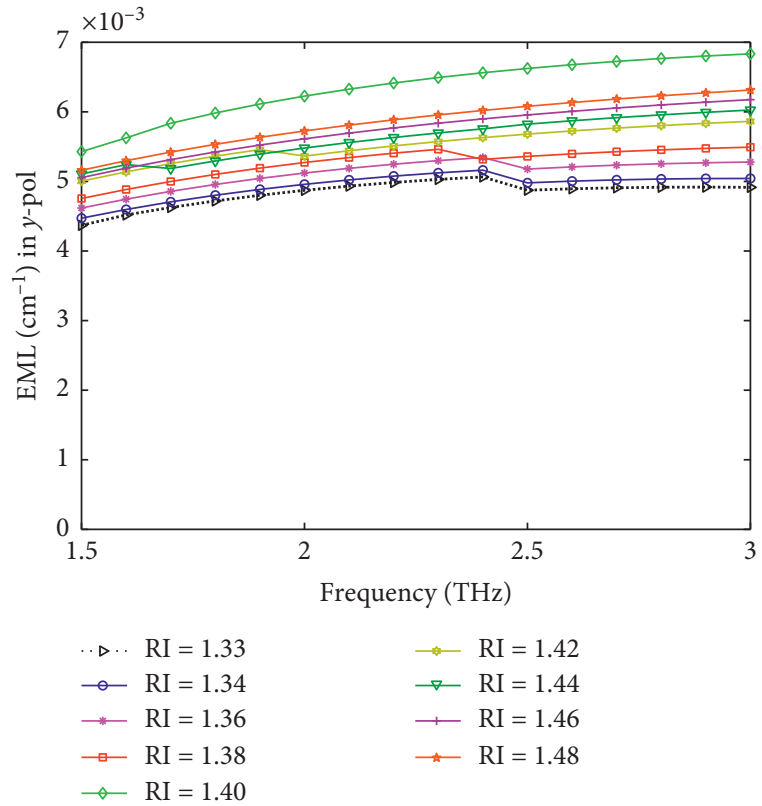

(b)

Figure 17: Comparison of the EML of the proposed BCS for different analytes in the THz band. (a) $x$-PoM and (b) $y$-PoM.

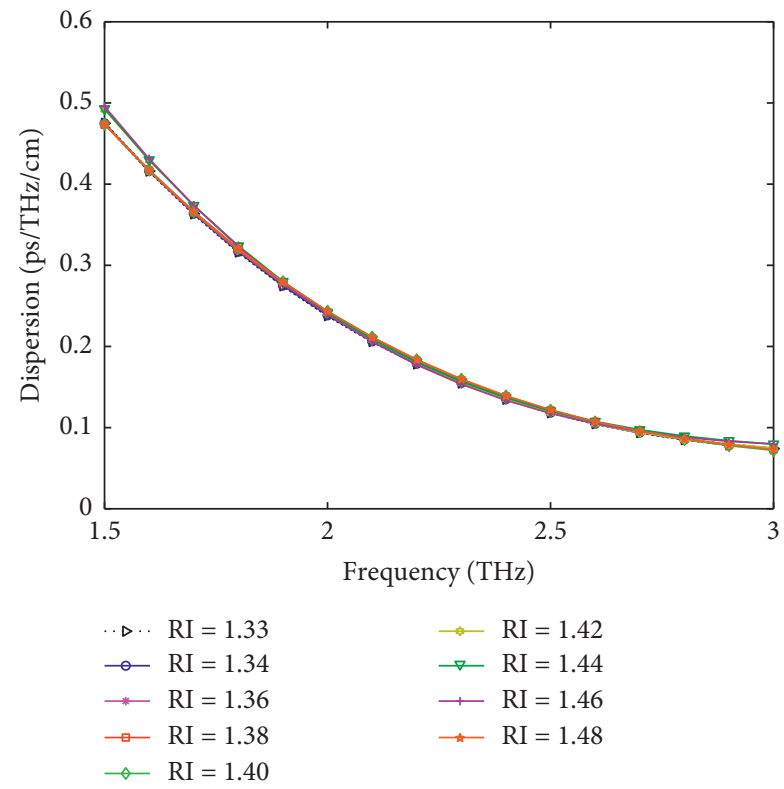

FIGURE 18: Representation of the dispersion of the proposed model in the THz band for different analytes.

with RI $1.33,1.34,1.36,1.38,1.40,1.42,1.44,1.46$, and 1.48 , respectively, in the $x$-PoM at $2.5 \mathrm{THz}$.

The relative sensitivity profile in the $x$ - and $y$-PoM are revealed in Figures 20(a) and 20(b), respectively. The proposed model shows higher relative sensitivity for the chemicals with higher RI. The relative sensitivities are $92.45,92.79,93.41,93.95,94.42,94.83,95.20,95.53$, and $95.82 \%$ for the analytes with RI $1.33,1.34,1.36,1.38,1.40$,
$1.42,1.44,1.46$, and 1.48 , respectively, in the $x$-PoM at $2.5 \mathrm{THz}$, whereas in the $y$-PoM, the proposed BCS has attained slightly lower relative sensitivities compared with the $x$-PoM.

The numerical comparison of the optical parameters for different analytes is presented in Table 4 .

The performance indices of the proposed BCS are compared with the other sensors in Table 5. Compared with 

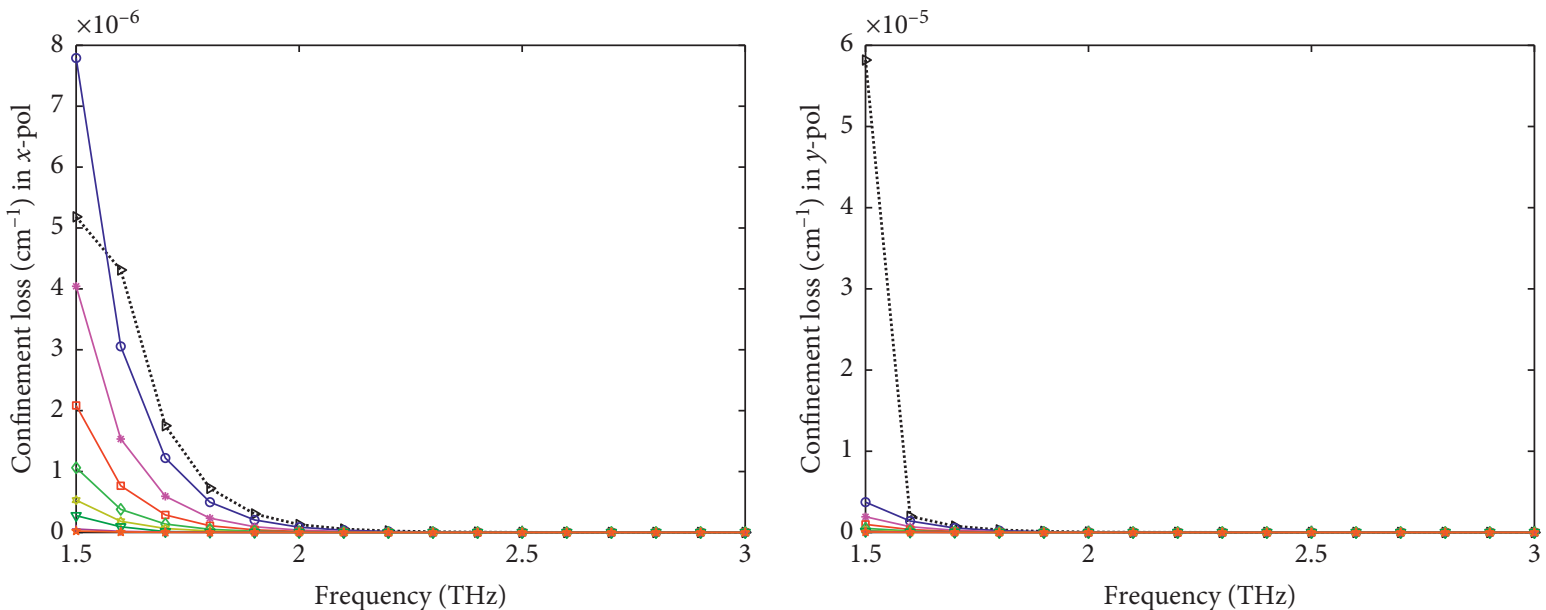

$$
\begin{array}{ll}
\rightarrow \triangleright \quad \mathrm{RI}=1.33 \\
\rightarrow \mathrm{RI}=1.34 \\
\rightarrow \mathrm{RI}=1.36 \\
\rightarrow \mathrm{RI}=1.38 \\
\rightarrow \mathrm{RI}=1.40
\end{array}
$$$$
\rightarrow \mathrm{RI}=1.42
$$$$
\rightarrow \mathrm{RI}=1.44
$$$$
\rightarrow \mathrm{RI}=1.46
$$$$
\rightarrow \mathrm{RI}=1.48
$$

(a)

$$
\begin{array}{ll}
\because \triangleright . & R I=1.33 \\
\rightarrow & R I=1.34 \\
\rightarrow- & R I=1.36 \\
\rightarrow- & R I=1.38 \\
\rightarrow & R I=1.40
\end{array}
$$

$$
\begin{aligned}
& \rightarrow \mathrm{RI}=1.42 \\
& \rightarrow \mathrm{RI}=1.44 \\
& \rightarrow \mathrm{RI}=1.46 \\
& \rightarrow \mathrm{RI}=1.48
\end{aligned}
$$

(b)

Figure 19: Comparison of the CL of the proposed model in the THz band for different analytes. (a) $x$-PoM and (b) $y$-PoM.

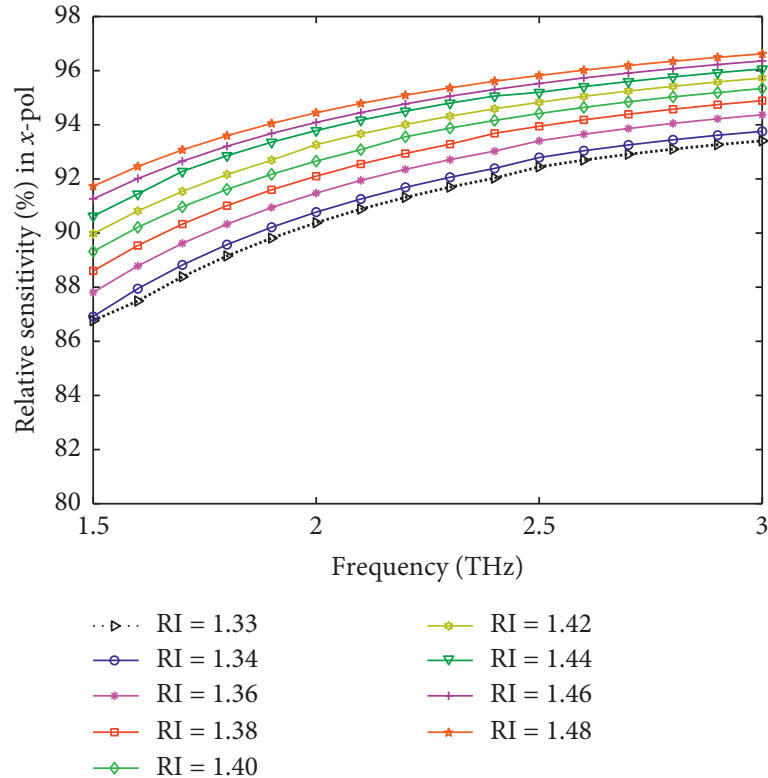

(a)

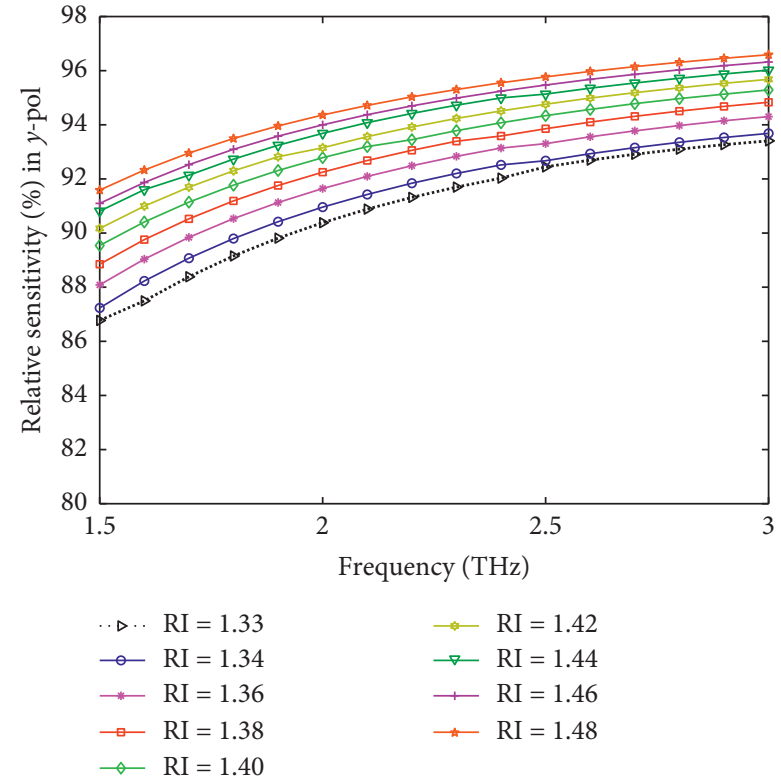

(b)

FIgURe 20: Depiction of the relative sensitivity profiles of the proposed model for different analytes. (a) $x$-PoM and (b) $y$-PoM.

TABLE 4: Comparison of the sensing performance of the proposed model for different analytes at $2.5 \mathrm{THz}$.

\begin{tabular}{lcccccccccc}
\hline $\mathrm{RI}$ & EffA $_{X}\left(\mu \mathrm{m}^{2}\right)$ & $\mathrm{EffA}_{Y}\left(\mu \mathrm{m}^{2}\right)$ & $\mathrm{NA}$ & $\mathrm{EML}_{X}\left(\mathrm{~cm}^{-1}\right)$ & $\mathrm{EML}_{Y}\left(\mathrm{~cm}^{-1}\right)$ & $\begin{array}{c}\text { Dispersion } \\
(\mathrm{ps} / \mathrm{THz} / \mathrm{cm})\end{array}$ & $\mathrm{CL}_{X}\left(\mathrm{~cm}^{-1}\right)$ & $\mathrm{CL}_{Y}\left(\mathrm{~cm}^{-1}\right)$ & $\mathrm{RS}_{X}(\%)$ & $\mathrm{RS}_{Y}(\%)$ \\
\hline $\mathbf{1 . 3 3}$ & 104980 & 103690 & 0.2045 & 0.0051 & 0.0049 & $0.1185 \pm 0.01225$ & $6.92 \times 10^{-10}$ & $2.10 \times 10^{-09}$ & 92.45 & 92.45 \\
$\mathbf{1 . 3 4}$ & 104310 & 103290 & 0.2052 & 0.0052 & 0.005 & $0.1185 \pm 0.0123$ & $4.28 \times 10^{-10}$ & $1.28 \times 10^{-09}$ & 92.79 & 92.67 \\
$\mathbf{1 . 3 6}$ & 103050 & 102460 & 0.2064 & 0.0054 & 0.0052 & $0.1201 \pm 0.0127$ & $1.64 \times 10^{-10}$ & $4.80 \times 10^{-10}$ & 93.41 & 93.30 \\
$\mathbf{1 . 3 8}$ & 101910 & 101610 & 0.2075 & 0.0056 & 0.0054 & $0.1212 \pm 0.0129$ & $6.30 \times 10^{-11}$ & $1.80 \times 10^{-10}$ & 93.95 & 93.85 \\
$\mathbf{1 . 4 0}$ & 100850 & 100760 & 0.2085 & 0.0057 & 0.0066 & $0.1215 \pm 0.01325$ & $2.40 \times 10^{-11}$ & $6.70 \times 10^{-11}$ & 94.42 & 94.34 \\
$\mathbf{1 . 4 2}$ & 99880 & 99931 & 0.2095 & 0.0059 & 0.0057 & $0.1184 \pm 0.01215$ & $8.90 \times 10^{-12}$ & $2.50 \times 10^{-11}$ & 94.83 & 94.76 \\
$\mathbf{1 . 4 4}$ & 98975 & 99121 & 0.2104 & 0.006 & 0.0058 & $0.1206 \pm 0.0116$ & $3.20 \times 10^{-12}$ & $9.00 \times 10^{-12}$ & 95.20 & 95.13 \\
$\mathbf{1 . 4 6}$ & 98130 & 98340 & 0.2112 & 0.0061 & 0.006 & $0.1176 \pm 0.0112$ & $1.10 \times 10^{-12}$ & $3.00 \times 10^{-12}$ & 95.53 & 95.47 \\
$\mathbf{1 . 4 8}$ & 97341 & 97590 & 0.2121 & 0.0062 & 0.0061 & $0.122 \pm 0.0131$ & $3.00 \times 10^{-13}$ & $1.00 \times 10^{-12}$ & 95.82 & 95.77 \\
\hline
\end{tabular}


TABLE 5: Comparison of the proposed BCS with existing sensors.

\begin{tabular}{|c|c|c|c|c|c|c|c|c|}
\hline Ref. & RI & Freq. (THz) & EffA $\left(\mu \mathrm{m}^{2}\right)$ & NA & $\operatorname{EML}\left(\mathrm{cm}^{-1}\right)$ & $\begin{array}{c}\text { Dispersion } \\
(\mathrm{ps} / \mathrm{THz} / \mathrm{cm})\end{array}$ & ConfL $\left(\mathrm{cm}^{-1}\right)$ & Sensitivity (\%) \\
\hline [5] & $1.33,1.35,1.38$ & 1.5 & 166000 & - & - & 20 & $2.93 \times 10^{-14}$ & 79.91 \\
\hline [32] & $1.33,1.354,1.366$ & 1.0 & 144000 & - & - & - & $2.5 \times 10^{-14}$ & 63.24 \\
\hline [14] & $1.366,1.394,1.44$ & 1.8 & - & - & 0.009 & - & $1.71 \times 10^{-14}$ & 94.40 \\
\hline [33] & $1.3326-1.3505$ & 1.8 & 397340 & - & 0.004 & - & $4.87 \times 10^{-11}$ & 91.50 \\
\hline [34] & $1.33,1.354,1.366$ & 1.0 & - & - & - & - & $3.02 \times 10^{-8}$ & 78.06 \\
\hline [69] & $1.33,1.354,1.366$ & 1.7 & - & 0.42 & 0.028 & 0.275 & $1.23 \times 10^{-8}$ & $89.00 \%$ \\
\hline$[70]$ & $1.41,1.45$ & 2.5 & - & - & 0.028 & - & $5.00 \times 10^{-15}$ & 89.00 \\
\hline Proposed BCS & $1.33-1.48$ & 2.5 & 97341 & 0.2121 & 0.0051 & $0.1176 \pm 0.0112$ & $3.00 \times 10^{-13}$ & 95.82 \\
\hline
\end{tabular}

the other sensors, the proposed model has typical values for all the optical parameters.

\section{Conclusions}

This paper presents a simple rectangular-based BCS operating in the $\mathrm{THz}$ regime. This BCS can effectively be applied for both biocomponents and chemicals detection purposes. The sensing performance of this sensor is evaluated for the frequency band that ranges from 1.5 to $3.0 \mathrm{THz}$. Besides, the proposed BCS comprises a simple arrangement of rectangles, which will ensure the feasible fabrication of this sensor. The sensor attains a maximum of $95.82 \%$ relative sensitivity at $2.5 \mathrm{THz}$. Also, this sensor suffers from a negligible amount of EML and CL. Due to its ultra-lower losses and ultrahigher relative sensitivities, this BCS model can effectively and efficiently be applied in biochemical sensing applications for different samples with dissimilar RI ranging from 1.33 to 1.48

\section{Data Availability}

This is a simulation-based study, and no external data have been used.

\section{Conflicts of Interest}

The authors declare no conflicts of interest.

\section{Authors' Contributions}

Abdullah Al-Mamun Bulbul, Abbas Z. Kouzani, M. A. Parvez Mahmud, and Abdullah-Al Nahid conceptualized the study. Formal analysis was performed by Abdullah Al-Mamun Bulbul. Funding acquisition was done by Abbas Z. Kouzani and M. A. Parvez Mahmud. Abdullah Al-Mamun Bulbul and Abdullah-Al Nahid investigated the study. Methodology was developed by Abdullah Al-Mamun Bulbul, M. A. Parvez Mahmud, and Abdullah-Al Nahid. Project administration was carried out by Abbas Z. Kouzani and M. A. Parvez Mahmud. Resources were obtained by Abbas Z. Kouzani and M. A. Parvez Mahmud. Supervision was done by Abbas Z. Kouzani, M. A. Parvez Mahmud, and Abdullah-Al Nahid. Abbas Z. Kouzani and Abdullah-Al Nahid validated the study results. Abdullah Al-Mamun Bulbul, M. A. Parvez Mahmud, and Abdullah-Al Nahid contributed to study visualization.
Writing of original draft was performed by Abdullah AlMamun Bulbul and Abdullah-Al Nahid. Review and editing were done by Abbas Z. Kouzani and M. A. Parvez Mahmud.

\section{Acknowledgments}

The authors are grateful to Deakin University, Geelong, VIC 3216, for providing resources for this research.

\section{References}

[1] A. A. Rifat, G. A. Mahdiraji, Y. M. Sua et al., "Surface plasmon resonance photonic crystal fiber biosensor: a practical sensing approach," IEEE Photonics Technology Letters, vol. 27, no. 15, pp. 1628-1631, 2015.

[2] P. Sharma and P. Sharan, "Design of photonic crystal-based biosensor for detection of glucose concentration in urine," IEEE Sensors Journal, vol. 15, no. 2, pp. 1035-1042, 2014.

[3] V. Kaur and S. Singh, "Design approach of solid-core photonic crystal fiber sensor with sensing ring for blood component detection," Journal of Nanophotonics, vol. 13, no. 2, Article ID 026011, 2019.

[4] E. Podder, M. B. Hossain, R. H. Jibon, A. A.-M. Bulbul, and H. S. Mondal, "Chemical sensing through photonic crystal fiber: sulfuric acid detection," Frontiers of Optoelectronics, vol. 12, no. 4, pp. 372-381, 2019.

[5] K. Ahmed, F. Ahmed, S. Roy et al., "Refractive index-based blood components sensing in terahertz spectrum," IEEE Sensors Journal, vol. 19, no. 9, pp. 3368-3375, 2019.

[6] M. S. Islam, M. Faisal, and S. A. Razzak, "Dispersion flattened extremely high-birefringent kagome lattice elliptic core photonic crystal fiber in $\mathrm{THz}$ regime," Optical and Quantum Electronics, vol. 51, no. 1, p. 35, 2019.

[7] F. A. Mou, M. M. Rahman, M. R. Islam, and M. I. H. Bhuiyan, "Development of a photonic crystal fiber for $\mathrm{THz}$ wave guidance and environmental pollutants detection," Sensing and Bio-Sensing Research, vol. 29, p. 100346, 2020.

[8] A. A.-M. Bulbul, F. Imam, M. A. Awal, and M. A. P. Mahmud, "A novel ultra-low loss rectangle-based porous-core PCF for efficient $\mathrm{THz}$ waveguidance: design and numerical analysis," Sensors, vol. 20, no. 22, p. 6500, 2020.

[9] B. Hong, M. Swithenbank, N. Greenall et al., "Low-loss asymptotically single-mode $\mathrm{THz}$ Bragg fiber fabricated by digital light processing rapid prototyping," IEEE Transactions on Terahertz Science and Technology, vol. 8, no. 1, pp. 90-99, 2017. 
[10] K. Wang and D. M. Mittleman, "Metal wires for terahertz wave guiding," Nature, vol. 432, no. 7015, pp. 376-379, 2004.

[11] J. A. Harrington, R. George, P. Pedersen, and E. Mueller, "Hollow polycarbonate waveguides with inner $\mathrm{Cu}$ coatings for delivery of terahertz radiation," Optics Express, vol. 12, no. 21, pp. 5263-5268, 2004.

[12] M. De, A. K. Pathak, and V. K. Singh, "Single channel photonic crystal fiber based high sensitive petrol adulteration detection sensor," Optik, vol. 183, pp. 539-546, 2019.

[13] D. Vigneswaran, N. Ayyanar, M. Sharma, M. Sumathi, M. S. Mani Rajan, and K. Porsezian, "Salinity sensor using photonic crystal fiber," Sensors and Actuators A: Physical, vol. 269, pp. 22-28, 2018.

[14] M. B. Hossain, E. Podder, A. A.-M. Bulbul, and H. S. Mondal, "Bane chemicals detection through photonic crystal fiber in THz regime," Optical Fiber Technology, vol. 54, Article ID 102102, 2020.

[15] M. M. Rahman, F. A. Mou, M. I. H. Bhuiyan, and M. R. Islam, "Photonic crystal fiber based terahertz sensor for cholesterol detection in human blood and liquid foodstuffs," Sensing and Bio-Sensing Research, vol. 29, Article ID 100356, 2020.

[16] B. M. Fischer, M. Hoffmann, H. Helm et al., "Terahertz timedomain spectroscopy and imaging of artificial RNA," Optics Express, vol. 13, no. 14, pp. 5205-5215, 2005.

[17] A. Markelz, A. Roitberg, and E. J. Heilweil, "Pulsed terahertz spectroscopy of DNA, bovine serum albumin and collagen between 0.1 and $2.0 \mathrm{THz}$," Chemical Physics Letters, vol. 320, no. 1-2, pp. 42-48, 2000.

[18] B. M. Fischer, M. Walther, and P. U. Jepsen, "Far-infrared vibrational modes of DNA components studied by terahertz time-domain spectroscopy," Physics in Medicine and Biology, vol. 47, no. 21, p. 3807, 2002.

[19] C. Yu, S. Fan, Y. Sun, and E. Pickwell-MacPherson, "The potential of terahertz imaging for cancer diagnosis: a review of investigations to date," Quantitative Imaging in Medicine and Surgery, vol. 2, no. 1, p. 33, 2012.

[20] A. Rahman, A. K. Rahman, and B. Rao, "Early detection of skin cancer via terahertz spectral profiling and 3D imaging," Biosensors and Bioelectronics, vol. 82, pp. 64-70, 2016.

[21] H. Cheon, H.-J. Yang, and J.-H. Son, "Toward clinical cancer imaging using terahertz spectroscopy," IEEE Journal of Selected Topics in Quantum Electronics, vol. 23, no. 4, pp. 1-9, 2017.

[22] E. Arik, C. Koral, H. Altan, and O. Esentürk, “A new method for alcohol content determination of fuel oils by terahertz spectroscopy," in Proceedings of the 2013 38th International Conference on Infrared, Millimeter, and Terahertz Waves (IRMMW-THz), p. 1, IEEE, Mainz, Germany, September 2013.

[23] J. Sultana, M. S. Islam, K. Ahmed, A. Dinovitser, B. W.-H. Ng, and D. Abbott, "Terahertz detection of alcohol using a photonic crystal fiber sensor," Applied Optics, vol. 57, no. 10, pp. 2426-2433, 2018.

[24] M. M. Rahman, F. A. Mou, A. Al Mahmud, and M. I. H. Bhuiyan, "Islam MR photonic crystal fiber based terahertz sensor for alcohol detection in beverages: design and analysis," in Proceedings of the 2019 IEEE International Conference on Telecommunications and Photonics (ICTP), pp. 1-4, IEEE, Dhaka, Bangladesh, December 2019.

[25] B. K. Paul, K. Ahmed, V. Dhasarathan, and T. K. Nguyen, "Oligoporous-core Quasi cladding photonic crystal fiber based micro-sensor for alcohol detection," Physica B: Condensed Matter, vol. 584, Article ID 412104, 2020.
[26] M. M. Eid, A. N. Z. Rashed, A. A.-M. Bulbul, and E. Podder, "Mono-rectangular core photonic crystal fiber (MRC-PCF) for skin and blood cancer detection," Plasmonics, pp. 1-11, 2020.

[27] M. F. H. Arif, M. M. Hossain, M. M. Rahman, and S. M. Khaled, "Photonic crystal based liquid sensor: a theoretical analysis for formalin detection," in Proceedings of the 2018 Joint 7th International Conference on Informatics, Electronics \& Vision (ICIEV) and 2018 2nd International Conference on Imaging, Vision \& Pattern Recognition (icIVPR), pp. 295-299, IEEE, Kitakyushu, Japan, June 2018.

[28] B. Abdullah Al-Mamun, J. Rayhan Habib, D. Sumon Kumar, R. Tonmoy, M. Avijit Saha, and M. Bellal Hossain, "PCF based formalin detection by exploring the optical properties in $\mathrm{THz}$ regime," Nanoscience \& Nanotechnology-Asia, vol. 10, pp. 1-8, 2020.

[29] Y. E. Monfared, M. Hajati, C. Liang, S. Yang, and M. Qasymeh, "Quasi-d-shaped fiber optic plasmonic biosensor for high-index analyte detection," IEEE Sensors Journal, vol. 21, no. 1, pp. 17-23, 2019.

[30] Y. E. Monfared, "Refractive index sensor based on surface plasmon resonance excitation in a D-shaped photonic crystal fiber coated by titanium nitride," Plasmonics, vol. 15, no. 2, pp. 535-542, 2020.

[31] Y. Esfahani Monfared, "Overview of recent advances in the design of plasmonic fiber-optic biosensors," Biosensors, vol. 10, no. 7, p. 77, 2020.

[32] M. M. Hasan, S. Sen, M. J. Rana et al., "Heptagonal photonic crystal fiber based chemical sensor in THz regime," in Proceedings of the 2019 Joint 8th International Conference on Informatics, Electronics \& Vision (ICIEV) and 2019 3rd International Conference on Imaging, Vision \& Pattern Recognition (icIVPR), pp. 40-44, IEEE, Phoenix, AZ, USA, April 2019.

[33] B. Abdullah Al-Mamun, M. Bellal Hossain, D. Rahul, and H. Mahadi, "Zeonex-based tetra-rectangular core-photonic crystal fiber for $\mathrm{NaCl}$ detection," Nanoscience \& Nanotechnology-Asia, vol. 10, pp. 1-9, 2020.

[34] M. Abdullah-Al-Shafi and S. Sen, "Design and analysis of a chemical sensing octagonal photonic crystal fiber (O-PCF) based optical sensor with high relative sensitivity for terahertz (THz) regime," Sensing and Bio-Sensing Research, vol. 29, Article ID 100372, 2020.

[35] T. Li, L. Zhu, X. Yang, X. Lou, and L. Yu, “A refractive index sensor based on $\mathrm{H}$-shaped photonic crystal fibers coated with Ag-graphene layers," Sensors, vol. 20, no. 3, p. 741, 2020.

[36] H. Han, D. Hou, L. Zhao et al., "A large detection-range plasmonic sensor based on an H-shaped photonic crystal fiber," Sensors, vol. 20, no. 4, p. 1009, 2020.

[37] J. N. Dash and R. Jha, "On the performance of graphene-based D-shaped photonic crystal fibre biosensor using surface plasmon resonance," Plasmonics, vol. 10, no. 5, pp. 1123-1131, 2015.

[38] J. N. Dash and R. Jha, "Graphene-based birefringent photonic crystal fiber sensor using surface plasmon resonance," IEEE Photonics Technology Letters, vol. 26, no. 11, pp. 1092-1095, 2014.

[39] X. Yu, Y. Zhang, S. Pan et al., "A selectively coated photonic crystal fiber based surface plasmon resonance sensor," Journal of Optics, vol. 12, no. 1, Article ID 015005, 2009.

[40] M. Erdmanis, D. Viegas, M. Hautakorpi, S. Novotny, J. L. Santos, and H. Ludvigsen, "Comprehensive numerical analysis of a surface-plasmon-resonance sensor based on an 
H-shaped optical fiber," Optics Express, vol. 19, no. 15, pp. 13980-13988, 2011.

[41] M. S. Islam, J. Sultana, A. A. Rifat, A. Dinovitser, B. Wai-Him $\mathrm{Ng}$, and D. Abbott, "Terahertz sensing in a hollow core photonic crystal fiber," IEEE Sensors Journal, vol. 18, no. 10, pp. 4073-4080, 2018.

[42] S. Nellen, B. Globisch, R. Kohlhaas, D. Stanze, T. Göbel, and L. Barry, "Schell M Fiber-coupled, photoconductive heterodyne receiver operating at frequencies up to $1 \mathrm{THz}$," in CLEO: Science and InnovationsOptical Society of America, Washington, DC, USA, 2017.

[43] F. Iqbal, S. Biswas, A. A.-M. Bulbul et al., "Alcohol sensing and classification using PCF-based sensor," Sensing and Bio-Sensing Research, vol. 30, Article ID 100384, 2020.

[44] M. R. Islam, M. F. Kabir, K. M. A. Talha, and M. S. Islam, “A novel hollow core terahertz refractometric sensor," Sensing and Bio-Sensing Research, vol. 25, Article ID 100295, 2019.

[45] V. Chaudhary, "Kumar D design and analysis of refractive index sensor based on dual-core photonic crystal fiber (DCPCF) with rectangular air hole lattice structure," in Optical and Wireless Technologies, pp. 207-213, Springer Singapore, Singapore, 2020.

[46] H. Ebendorff-Heidepriem, J. Schuppich, A. Dowler, L. LimaMarques, and T. M. Monro, "3D-printed extrusion dies: a versatile approach to optical material processing," Optical Materials Express, vol. 4, no. 8, pp. 1494-1504, 2014.

[47] T. Yang, C. Ding, R. W. Ziolkowski, and Y. J. Guo, “A terahertz (THz) single-polarization-single-mode (SPSM) photonic crystal fiber (PCF)," Materials, vol. 12, no. 15, p. 2442, 2019.

[48] M. S. Islam, J. Sultana, S. Rana et al., "Extremely low material loss and dispersion flattened TOPAS based circular porous fiber for long distance terahertz wave transmission," Optical Fiber Technology, vol. 34, pp. 6-11, 2017.

[49] J. Anthony, R. Leonhardt, A. Argyros, and M. C. J. Large, "Characterization of a microstructured Zeonex terahertz fiber," Journal of the Optical Society of America B, vol. 28, no. 5, pp. 1013-1018, 2011.

[50] G. Woyessa, A. Fasano, C. Markos, A. Stefani, H. K. Rasmussen, and O. Bang, "Zeonex microstructured polymer optical fiber: fabrication friendly fibers for high temperature and humidity insensitive Bragg grating sensing," Optical Materials Express, vol. 7, no. 1, pp. 286-295, 2017.

[51] M. A. Mollah, M. Yousufali, I. M. Ankan, M. M. Rahman, H. Sarker, and K. Chakrabarti, "Twin core photonic crystal fiber refractive index sensor for early detection of blood cancer," Sensing and Bio-Sensing Research, vol. 29, Article ID 100344, 2020.

[52] D. Wencel and C. McDonagh, "Optical chemical sensors: a look back," in Optochemical Nanosensors, pp. 70-117, CRC Press, Boca Raton, FL, USA, 2016.

[53] Y. Zhang, C. Shi, C. Gu, L. Seballos, and J. Z. Zhang, "Liquid core photonic crystal fiber sensor based on surface enhanced Raman scattering," Applied Physics Letters, vol. 90, no. 19, Article ID 193504, 2007.

[54] A. M. Pinto and M. Lopez-Amo, "Photonic crystal fibers for sensing applications," Journal of Sensors, vol. 2012, Article ID 598178, 21 pages, 2012.

[55] J. C. Knight, "Photonic crystal fibres," Nature, vol. 424, no. 6950, pp. 847-851, 2003.

[56] M. De, T. K. Gangopadhyay, and V. K. Singh, "Prospects of photonic crystal fiber as physical sensor: an overview," Sensors, vol. 19, no. 3, p. 464, 2019.
[57] P. Zhang, J. Zhang, P. Yang, S. Dai, X. Wang, and W. Zhang, "Fabrication of chalcogenide glass photonic crystal fibers with mechanical drilling," Optical Fiber Technology, vol. 26, pp. 176-179, 2015.

[58] R. T. Bise, "Trevor DJ Sol-gel derived microstructured fiber: fabrication and characterization," in Optical Fiber Communication Conferencep. OWL6, Optical Society of America, Washington, DC, USA, 2005.

[59] A. Ghazanfari, W. Li, M. C. Leu, and G. E. Hilmas, "A novel freeform extrusion fabrication process for producing solid ceramic components with uniform layered radiation drying," Additive Manufacturing, vol. 15, pp. 102-112, 2017.

[60] L. Xiao, W. Jin, M. S. Demokan, H. L. Ho, Y. L. Hoo, and C. Zhao, "Fabrication of selective injection microstructured optical fibers with a conventional fusion splicer," Optics Express, vol. 13, no. 22, pp. 9014-9022, 2005.

[61] W. Qian, C.-L. Zhao, Y. Wang, C. C. Chan, S. Liu, and W. Jin, "Partially liquid-filled hollow-core photonic crystal fiber polarizer," Optics Letters, vol. 36, no. 16, pp. 3296-3298, 2011.

[62] Y. Wang, C. R. Liao, and D. N. Wang, "Femtosecond laserassisted selective infiltration of microstructured optical fibers," Optics Express, vol. 18, no. 17, pp. 18056-18060, 2010.

[63] C.-L. Zhao, D. N. Wang, and L. Xiao, "Filling technologies of photonic crystal fibers and their applications," in Handbook of Optical Fibers, G.-D. Peng, Ed., Springer Singapore, Singapore, pp. 1-62, 2018.

[64] B. K. Paul, S. Chakma, M. A. Khalek, and K. Ahmed, "Silicon nano crystal filled ellipse core based quasi photonic crystal fiber with birefringence and very high nonlinearity," Chinese Journal of Physics, vol. 56, no. 6, pp. 2782-2788, 2018.

[65] A. Hassani, A. Dupuis, and M. Skorobogatiy, "Low loss porous terahertz fibers containing multiple subwavelength holes," Applied Physics Letters, vol. 92, no. 7, Article ID 071101, 2008

[66] M. S. Islam, S. Rana, M. R. Islam, M. Faisal, H. Rahman, and J. Sultana, "Porous core photonic crystal fibre for ultra-low material loss in THz regime," IET Communications, vol. 10, no. 16 , pp. 2179-2183, 2016.

[67] B. Fischer, M. Hoffmann, H. Helm, G. Modjesch, and P. U. Jepsen, "Chemical recognition in terahertz time-domain spectroscopy and imaging," Semiconductor Science and Technology, vol. 20, no. 7, p. S246, 2005.

[68] M. R. Hasan, M. S. Anower, M. A. Islam, and S. Razzak, "Polarization-maintaining low-loss porous-core spiral photonic crystal fiber for terahertz wave guidance," Applied Optics, vol. 55, no. 15, pp. 4145-4152, 2016.

[69] M. A. Habib, M. S. Anower, L. F. Abdulrazak, and M. S. Reza, "Hollow core photonic crystal fiber for chemical identification in terahertz regime," Optical Fiber Technology, vol. 52, Article ID 101933, 2019.

[70] M. S. Islam, J. Sultana, A. Dinovitser, K. Ahmed, B. W.-H. Ng, and D. Abbott, "Sensing of toxic chemicals using polarized photonic crystal fiber in the terahertz regime," Optics Communications, vol. 426, pp. 341-347, 2018. 